\title{
MAPEAMENTO DE FRAGILIDADE AMBIENTAL POR MEIO DE ANÁLISE GEOESPACIAL: UMA APLICAÇÃO NA ALTA BACIA DOS RIOS PIRACICABA E SAPUCAÍ-MIRIM, APA FERNÃO DIAS, MG
}

\author{
Danilo Trovó Garófalo \\ Marcos César Ferreira²
}

Resumo: O objetivo deste artigo é apresentar um procedimento metodológico desenvolvido por meio de técnicas de análise geoespacial em SIG, para o mapeamento da fragilidade ambiental. Este procedimento utiliza as seguintes variáveis geoambientais: índice de vegetação (NDVI), probabilidade de ocorrência de chuvas intensas, declividade do terreno, densidade de lineamentos estruturais e densidade de estradas. $O$ peso atribuído a estas variáveis é estimado por meio do parâmetro $D$, calculado a partir do teste estatístico Kolmogorov-Smirnov, realizado entre cada variável geoambiental e a frequência de ravinas e movimentos de massa mapeados em imagens Google Earth e checados posteriormente em campo. Os mapas originais das variáveis geoambientais são convertidos em valores fuzzy por meio de funções de afinidade lineares. Esta proposta foi testada na área de proteção ambiental (APA) Fernão Dias, situada no sul do estado de Minas Gerais. Os resultados indicam que as áreas situadas no centro-leste da APA são as mais frágeis, mesmo apresentando remanescentes florestais significativos. Já a oeste da APA, principalmente nas imediações da rodovia Fernão Dias, as áreas de alta fragilidade ocorrem em áreas onde a expansão urbana é mais desordenada e em áreas com grande densidade de culturas anuais, pastagens degradadas e estradas vicinais sem pavimentação. Esta metodologia pode ser utilizada como auxílio às metodologias já tradicionalmente.

Palavras-chave: APA Fernão Dias; Fragilidade Ambiental; Mapeamento de risco; SIG; Teste Estatístico Kolmogorov-Smirnov; Análise geoespacial.

\section{Environmental fragility mapping using geospatial analysis: an application on Piracicaba and Sapucai upper river basins, Fernao Dias EPA, MG, Brazil}

\begin{abstract}
The aim of this paper is to present a methodological approach based on geospatial analysis techniques and GIS, for environmental fragility mapping. This procedure uses the following geoenvironmental variables: NDVI vegetation index, heavy rains probability, terrain slope, structural lineaments density and road density. The weights assigned to these variables are estimated using $D$ parameter, calculated from the Kolmogorov-Smirnov test. This test uses the geoenvironmental variables above cited, mass movements and gullies mapped on Google Earth images and checked in the field. The geoenvironmental variables
\end{abstract}

1. Doutorando do Programa de Pós-Graduação em Geografia, Instituto de Geociências, Unicamp (danilogarofalo@ige.unicamp.br).

2. Professor Associado do Departamento de Geografia, Instituto de Geociências, Unicamp (macferre@uol.com.br) 
maps were converted to the fuzzy values using linear membership functions. This model was tested in the Fernao Dias environmental protection area (EPA), located at southern Minas Gerais state. The results indicate that the areas located in the center-east of the EPA are the most fragile, even having significant remaining forest areas. In the west of EPA, mainly nearby Fernao Dias highway, the high fragility areas occur where urban sprawl is not planned, in croplands, degraded pastures and in the no-pavement roads high-density areas.

Key words: Fernao Dias, EPA, Environmental Fragility, Risk Mapping, GIS, KolmogorovSmirnov Test, Spatial Analysis.

\section{INTRODUÇÃO}

A fragmentação florestal e a remoção da cobertura vegetal remanescente em algumas áreas do Brasil têm causado aumento significativo dos processos erosivos e provocado alterações na dinâmica hidrológica e geomorfológica dos sistemas ambientais. Por esta razão, torna-se cada vez mais imprescindível um planejamento físico-territorial que considere potencialidades, limitações e a vulnerabilidade destas áreas frente às intervenções antrópicas ainda persistentes.

$\mathrm{Na}$ literatura brasileira são encontrados três modelos para elaboração de mapas de fragilidade ambiental, amplamente utilizados por pesquisadores e gestores brasileiros, propostos por Ross (1994) e Crepaniet al. (1996). Nos dois modelos de Ross (1994), denominados Fragilidade Potencial Natural baseada em Índices de Dissecação do Relevo e Fragilidade Potencial Natural baseada nas Classes de Declividade, a fragilidade dos ambientes naturais é determinada a partir de elementos geomorfológicos (dissecação do relevo e classe de declividade), solos, cobertura vegetal, uso do solo e clima. Nestes dois modelos as variáveis são agrupadas em cinco classes, de acordo com sua contribuição à fragilidade ambiental: muito fraca (1), fraca (2), média (3), forte (4) e muito forte (5).

O modelo de Fragilidade Potencial Natural Baseado em Unidades Territoriais Básicas,proposto por Crepani et al. (1996) é construído a partir do mapa de Unidades Territoriais Básicas, definidas a partir da análise de imagens orbitais Landsat. A fragilidade potencial natural das Unidades Territoriais Básicas é definida pela análise conjunta das variáveis rocha, solo, relevo, vegetação e clima,de modo que cada uma destas variáveis receba um grau de fragilidade, que varia de 1 a 3. 
Spörl e Ross (2004) avaliaram comparativamente estes três modelos de fragilidade ambiental. Os autores constataram que o principal problema destes métodos está relacionado à atribuição de pesos às variáveis utilizadas nos modelos, e destacam que esta atribuição é, em geral, subjetiva, em razão da complexidade em se aferir a contribuição de cada variável a níveis de fragilidade ambiental. Além disso, os três modelos são construídos com base no mesmo princípio de delimitação de áreas: as unidades eco dinâmicas de Tricart (1977) (SPÖRL, 2001). De acordo com Calijuri et al. (2007), as principais deficiências relacionadas à definição de limites rígidos são os erros e as incertezas a eles associados, pois nem sempre os fenômenos naturais são devidamente representados com exatidão.

O objetivo deste artigo é apresentar um procedimento alternativo para mapeamento da fragilidade ambiental, baseado em técnicas de análise geoespacial processadas em sistema de informação geográfica. As principais particularidades deste procedimento são:

a) Estimação do valor dos pesos das variáveis por análise estatística, adequados às especificidades locais;

b) Utilização de classificação contínua para a representação da fragilidade ambiental; e,

c) Possibilidade de se mapear de fragilidade ambiental em situações em que mapas pedológicos e geológicos não sejam disponíveis em escala adequada.

Este procedimento foi testado na Área de Proteção Ambiental (APA) Fernão Dias-MG, situada no sul do estado de Minas Gerais, junto à divisa com o estado de São Paulo (Figura 1). Esta APA ocupa superfície de 180.373 hectares e distribui-se integralmente pelos municípios de Camanducaia, Extrema, Gonçalves, Itapeva, Sapucaí-Mirim e Toledo, e,parcialmente, pelos municípios de Brasópolis e Paraisópolis.

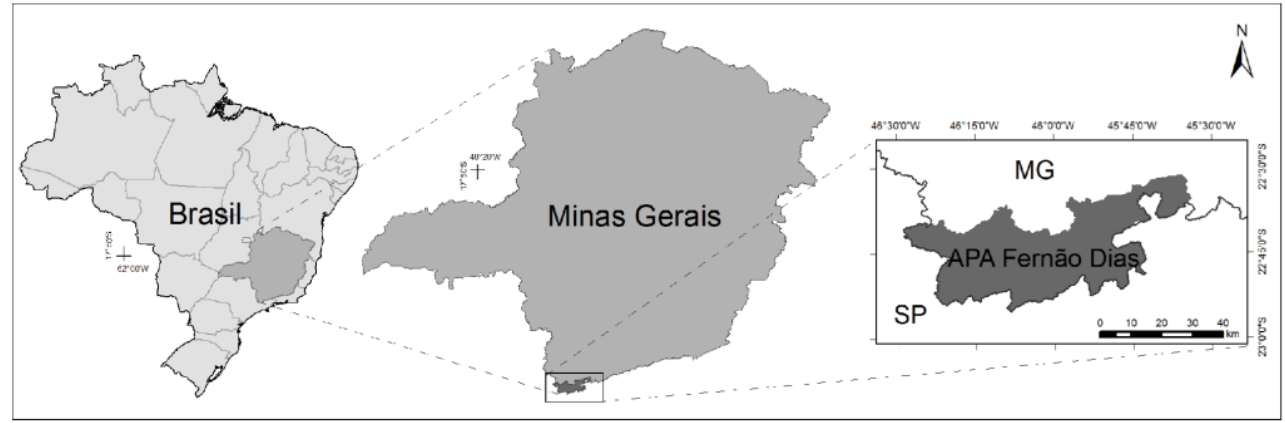

Figura 1: Localização da APA Fernão Dias-MG. Fonte: Autores 


\section{REVISÃO DOS CONHECIMENTOS ANTERIORES}

A definição de diferentes níveis de fragilidade de um determinado espaço, considerando seus componentes físicos, bióticos e antrópicos, depende da necessidade de se conjugar, dentro de uma análise, os respectivos valores e as importâncias de cada variável com relação à fragilidade ambiental (MIARA, 2007). Contudo, estabelecer uma relação de importância entre as variáveis, e que mais se assemelhe à realidade, é uma tarefa complexa. De acordo com Coelho (2011), tal ponderação pode ser estabelecida de três maneiras: análise estatística; julgamento de especialistas sobre o assunto; e através de legislação pertinente ou metodologias que já apresentam um determinado peso para cada variável.

Quanto à ponderação por meio de opinião de especialista, um procedimento muito utilizado em estudos ambientais é o método Delphi.

O método Delphi na obtenção de pesos baseia-se na escolha de um grupo multidisciplinar de especialistas, que conheçam bem o fenômeno e melhor ainda se conhecerem bem a realidade espacial onde ele se localiza. A esses especialistas é solicitado que hierarquizem ou coloquem as variáveis em ordem de importância para a manifestação ou ocorrência do fenômeno em estudo (MOURA, 2007).

Kheir et al. (2006) elaboraram um modelo para mapear o risco de erosão do solo em uma área situada no Líbano, baseado em três mapas: potencial de escoamento (estimado a partir da precipitação média anual, capacidade de retenção de água no solo e capacidade de infiltração do solo); sensibilidade da paisagem (baseado na cobertura vegetal, densidade de drenagem e declividade); e erodibilidade de rochas e do solo. Dois novos mapas temáticos foram derivados: sensibilidade potencial à erosão, obtido a partir dos mapas de potencial de escoamento e de sensibilidade paisagem; e risco de erosão, estimado a partir do potencial de erosão e erodibilidade. O modelo elaborado por Kheir et al. (2006) utilizou regras de decisão qualitativas e organização hierárquica de parâmetros, com base no conhecimento de especialistas (método Delphi). Os autores apontam que os resultados são satisfatórios, mas reconhecem que o método emprega procedimentos qualitativos e relativamente subjetivos. 
Nigel e Rughooputh (2010) mapearam o risco de erosão mensal do solo nas Ilhas Maurícia, a partir de um modelo denominado MauSERM (MauritiusSoilErosionRiskMapping), que combina,por meio de regras de decisão e álgebra de mapas em ambiente SIG,o volume mensal de precipitação, tipo de solo, declividade e cobertura mensal do solo. A influência de cada variável no risco à erosão é determinada por julgamento de especialistas. Neste modelo, a declividade combinada ao tipo de solo resulta no mapa de susceptibilidade a erosão do solo; este mapa, em conjunto com a cobertura do solo,gera o mapa de sensibilidade erosiva, que, combinado ao mapa de chuvas, produz o mapa de risco de erosão.

A atribuição de peso com base em legislação pertinente, ou em metodologias que estabeleçam previamente pesos a variáveis, também tendem a ser subjetivas, uma vez que os pesos são geralmente determinados a partir de evidências empíricas, o que onera a sua generalização a contextos distintos dos originais (COELHO, 2011), a exemplo das metodologias propostas por Ross (1994) e Crepani et al. (1996).

Outra metodologia que utiliza de variáveis já ponderadas e destinadas ao estudo de perdas de solo por processos erosivos, é a Equação Universal de Perdas de Solo - USLE, desenvolvida nos anos 1970 por Wischmeiere Smith (1978). Esta equação baseia-se no produto de coeficientes empíricos relativos a fatores influenciadores da erosão, tais como: erosividade da chuva; erodibilidade do solo; fator topográfico; fator de cobertura vegetal e práticas conservacionistas (SILVA, 1978; BERTONI e LOMBARDI NETO 1999; 144 PRADO e NÓBREGA, 2005; AMORIM e SILVA, 2009).

Já a atribuição de pesos a partir de análises estatísticas identifica as situações nas quais existe alta correlação das variáveis com o fenômeno ou ocorrência a ser explicado, atribuindo-se maior peso às variáveis que apresentam elevada correlação com o fenômeno em estudo (MOURA, 2007). Contudo, ainda há um determinado nível de subjetividade, pois, a própria escolha do modelo estatístico depende da opinião de um especialista (MOURA, 2010), além da seleção das variáveis utilizadas no modelo.

Conoscenti et al. (2014) caracterizaram as condições de susceptibilidade à erosão por ravina na bacia hidrográfica do rio San Giorgio, centro-norte da Sicília, Itália, aplicando análise estatística multivariada. Por meio de imagens aéreas os autores identificaram 260 ravinas na 
área de estudo,e selecionaram 27 atributos ambientais que descrevem a variabilidade da litologia, uso do solo, topografia e distância de estradas. As relações funcionais entre ocorrência de ravinas e os fatores de controle - variáveis explicativas - foram obtidos a partir de regressão logística para calcular a probabilidade de ocorrência de ravina em dois tipos diferentes de unidades de mapeamento: células de grade e unidades de vertente. A fim de treinar e testar os modelos preditivos, os autores selecionaram, aleatoriamente, três subconjuntos de validação e três subconjuntos calibração. Os resultados da validação indicaram que os modelos foram precisos, mostrando melhor habilidade preditiva e desempenho mais estável do modelo de susceptibilidade com base em células de grade.

Conoscenti et al. (2014) apresentam uma síntese de vários trabalhos que aplicam métodos estatísticos para prever a distribuição espacial de processos erosivos em várias escalas espaciais (Tabela 1).

Outro teste estatístico que pode ser aplicado à atribuição de pesos às variáveis geoambientais é o teste Kolmogorov-Smirnov. Este teste baseia-se na medida da diferença absoluta máxima entre as funções de distribuição cumulativas das amostras de cada população (EVERITT, 2006). Como critério, compara-se esta diferença com um valor crítico para um dado nível de significância, com base em tabela estatística adequada.

\begin{tabular}{|c|c|c|c|}
\hline ARTIGO & ESCALA & ÁREA $\left(\mathrm{km}^{2}\right)$ & MÉTODOS \\
\hline Akgün e Turk (2011) & Regional & 424 & Regressão logística \\
\hline BouKheir et al. (2007) & Regional & 676 & Classificação e árvore de regressão \\
\hline Chaplot et al. (2005) & Bacia & 0,62 & Regressão linear \\
\hline Conforti et al. (2010) & Bacia & 30 & Valor Informação \\
\hline Conoscenti et al. (2008) & Bacia & 225 & Análise condicional \\
\hline Conoscenti et al. (2013) & Bacia & 250 & Análise condicional \\
\hline Geissen et al. (2007) & Regional & 3500 & Classificação e árvore de regressão \\
\hline Gómez Gutiérrez et al. (2009a) & Fazenda & 26,4 (ha) & Regressão adaptativa multivariada \\
\hline Gómez Gutiérrez et al. (2009b) & Fazenda & 26,4 (ha) & Regressão adaptativa multivariada \\
\hline Hughes et al. (2001) & Continental & $1,7 \times 106$ & Densidade de erosão \\
\hline Lucà et al. (2011) & Bacia & 30 & $\begin{array}{l}\text { Valor da informação; regressão } \\
\text { logística. }\end{array}$ \\
\hline Magliulo $(2010,2012)$ & Bacia & 10,5 & Análise condicional \\
\hline Märker et al. (2011) & Bacia & 42 & Classificação e árvore de regressão \\
\hline Meyer et al. (1999) & Parcela & $\begin{array}{r}\text { Não } \\
\text { reportado }\end{array}$ & Regressão logística \\
\hline
\end{tabular}

Tabela 1: Relação de trabalhos que aplicam métodos estatísticos para prever a distribuição espacial de processos erosivos.

Fonte: Modificado de Conoscenti et al. (2014). 


\section{MATERIAIS E MÉTODO}

Determinação dos pesos atribuídos às variáveis ambientais, baseada no teste estatístico Kolmogorov-Smirnov

Nossa hipótese de pesquisa é que a ocorrência de processos erosivos lineares (ravinas) e de movimentos de massa (escorregamentos) depende de cinco fatores: densidade da vegetação, declividade da vertente, probabilidade de ocorrência de chuvas intensas, densidade de lineamentos estruturais e densidade de vias de circulação. No Quadro 1 são apresentados os mapas temáticos e as principais características destes fatores. 
MAPEAMENTO DE FRAGILIDADE AMBIENTAL POR MEIO DE ANÁLISE GEOESPACIAL: UMA APLICAÇÃO NA ALTA BACIA DOS RIOS

PIRACICABA E SAPUCAÍ-MIRIM, APA FERNÃO DIAS, MG

DANILO TROVÓ GARÓFALO, MARCOS CÉSAR FERREIRA

Quadro 1: Variáveis geoambientais, suas justificativas de uso, métodos de elaboração e variáveis representadas em mapas temáticos.

Fonte: Autores.

\begin{tabular}{|c|c|c|c|}
\hline VARIÁVEL & JUSTIFICATIVA & MÉTODO & MAPA TEMÁTICO DA VARIÁVEL \\
\hline $\begin{array}{l}\text { ÍNDICE DE } \\
\text { VEGETAÇÃO }\end{array}$ & $\begin{array}{l}\text { Representa o percentual de } \\
\text { cobertura do solo pela vegetação } \\
\text { indiscriminada. Este fator está } \\
\text { diretamente relacionado à } \\
\text { interceptação das gotas de chuva e a } \\
\text { consequente minimização dos } \\
\text { processos erosivos e movimentos de } \\
\text { massa, (BIGARELLA, 2007). }\end{array}$ & $\begin{array}{l}\text { Índice de Vegetação da Diferença } \\
\text { Normalizada (NDVI - Normalized } \\
\text { Difference Vegetation Index), obtido a } \\
\text { partir da razão entre a diferença da } \\
\text { reflectância do infravermelho próximo } \\
\text { (NIR) e do vermelho (VIS). } \\
\text { Essa diferença é normalizada pela divisão } \\
\text { da soma das faixas de NIR e VIS (ROUSE et } \\
\text { al., 1973). } \\
\text { Foram utilizadas as bandas } 3 \text { e } 4 \text { do TM/ } \\
\text { Landsat-5, de 18/04/2010. } \\
\text { A correção atmosférica foi realizada pelo } \\
\text { método do Pixel Escuro, proposto por } \\
\text { Chavez (1988). }\end{array}$ & 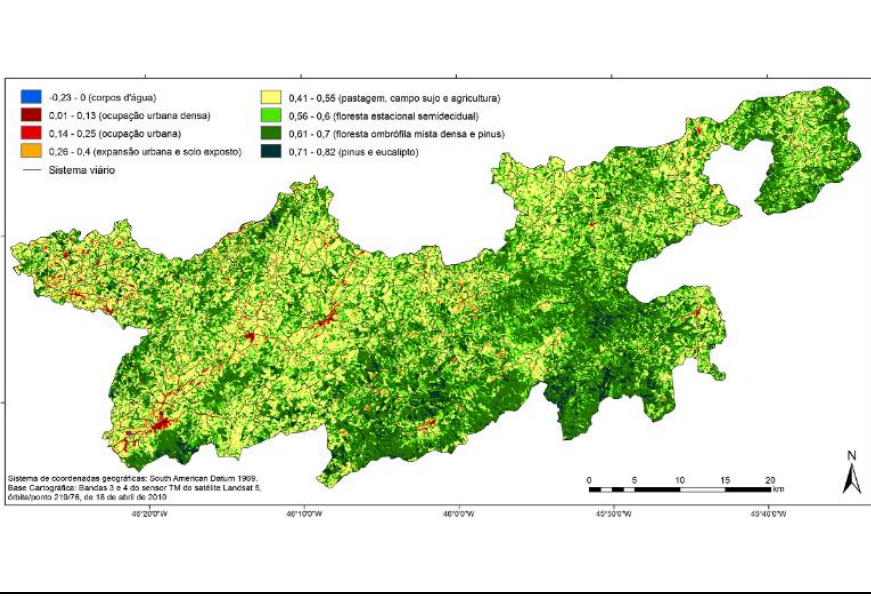 \\
\hline DECLIVIDADE & $\begin{array}{l}\text { A declividade é definida como } \\
\text { ângulo de inclinação (zenital) da } \\
\text { superfície do terreno em relação à } \\
\text { horizontal. } \\
\text { Possui estreita associação com } \\
\text { processos de transporte } \\
\text { gravitacional (escoamento, erosão, } \\
\text { escorregamento) (VALERIANO, } \\
\text { 2008). }\end{array}$ & $\begin{array}{l}\text { Declividade expressa em grau, calculada a } \\
\text { partir do comando Slope do SIG ArcGIS } \\
10^{\mathrm{TM}} \text { aplicado ao MDE ASTER GDEM I } \\
\text { (2009). } \\
\text { Tal comando utiliza a técnica média } \\
\text { máxima (BURROUGH e MCDONELL, 1998). }\end{array}$ & 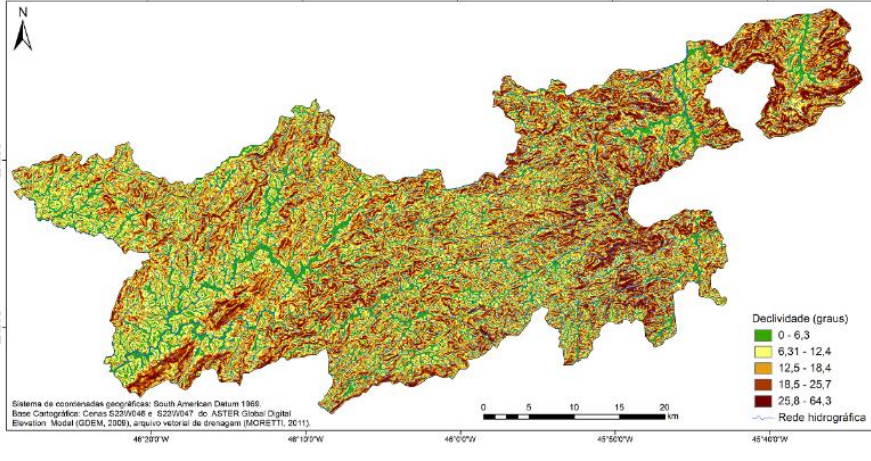 \\
\hline
\end{tabular}


MAPEAMENTO DE FRAGILIDADE AMBIENTAL POR MEIO DE ANÁLISE GEOESPACIAL: UMA APLICAÇÃO NA ALTA BACIA DOS RIOS

PIRACICABA E SAPUCAÍ-MIRIM, APA FERNÃO DIAS, MG

DANILO TROVÓ GARÓFALO, MARCOS CÉSAR FERREIRA

Quadro 1: Variáveis geoambientais, suas justificativas de uso, métodos de elaboração e variáveis representadas em mapas temáticos.

Fonte: Autores.

\begin{tabular}{|c|c|c|c|}
\hline VARIÁVEL & JUSTIFICATIVA & MÉTODO & MAPA TEMÁTICO DA VARIÁVEL \\
\hline $\begin{array}{l}\text { DENSIDADE DE } \\
\text { LINEAMENTOS } \\
\text { ESTRUTURAIS }\end{array}$ & $\begin{array}{l}\text { Os lineamentos estruturais } \\
\text { possibilitam maior percolação de } \\
\text { fluidos pelo sistema solo/rocha, } \\
\text { contribuindo no domínio da } \\
\text { morfogênese sobre a pedogênese, } \\
\text { aumentando a instabilidade das } \\
\text { vertentes a escorregamentos e a } \\
\text { possibilidade de erosão (SELBY, } \\
\text { 1982; FIORI, 1995; BIGARELLA, } \\
\text { 2007). }\end{array}$ & $\begin{array}{l}\text { Densidade de lineamentos expressa em } \\
\mathrm{Km} / \mathrm{km}^{2} \text {, calculada a partir do estimador } \\
\text { Kernel do SIG ArcGIS } 10^{\mathrm{TM}} \text { aplicado aos } \\
\text { lineamentos estruturais. } \\
\text { Os lineamentos foram traçados por meio } \\
\text { de interpretação visual dos elementos } \\
\text { texturais de relevo e drenagem, com } \\
\text { ênfase às quebras negativas de relevo } \\
\text { (fundo de vale) e, principalmente, à } \\
\text { estruturação da rede de drenagem } \\
\text { (SOARES e FIORI, 1976). }\end{array}$ & 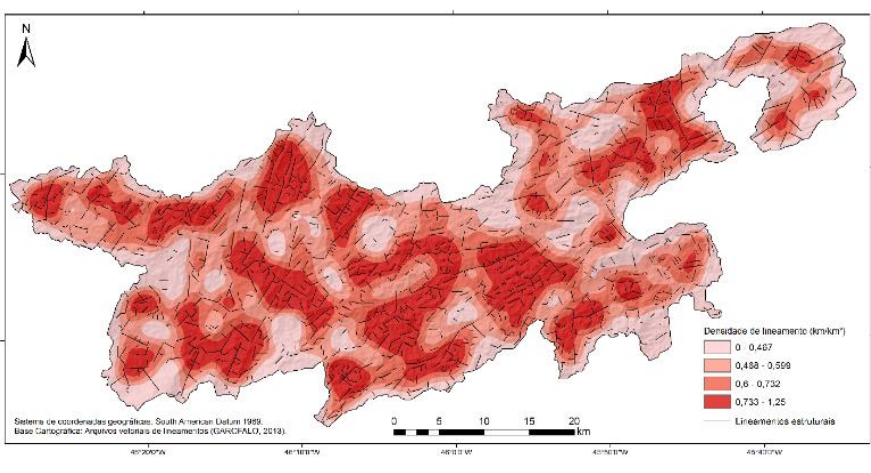 \\
\hline $\begin{array}{l}\text { DENSIDADE DE } \\
\text { VIAS DE } \\
\text { CIRCULAÇÃO }\end{array}$ & $\begin{array}{l}\text { As vias de circulação ao atravessar a } \\
\text { paisagem desviam as águas pluviais } \\
\text { do seu curso normal. } \\
\text { Se um sistema de drenagem não for } \\
\text { convenientemente estudado, haverá } \\
\text { a intensificação dos processos } \\
\text { morfodinâmicos (erosão e } \\
\text { movimentos de massa) e } \\
\text { hidrológicos locais, além de elevar o } \\
\text { pico de fluxos fluviais e de } \\
\text { sedimentos à jusante (FORMAN e } \\
\text { ALEXANDER, 1998; BIGARELLA, } \\
\text { 2007). }\end{array}$ & $\begin{array}{l}\text { Densidade de vias de circulação expressa } \\
\text { em } \mathrm{Km} / \mathrm{km}^{2} \text {, calculada a partir do } \\
\text { estimador Kernel do SIG ArcGIS } 10^{\mathrm{TM}} \\
\text { aplicado às vias, extraídas de cartas } \\
\text { topográficas produzidas na década de } \\
1970 \text { (IBGE) e atualizadas a partir de } \\
\text { composição colorida RGB } 357 \text { de cenas do } \\
\text { sensor TM do satélite Landsat } 5 \text { - } \\
\text { 18/04/2010. }\end{array}$ & trits \\
\hline
\end{tabular}


MAPEAMENTO DE FRAGILIDADE AMBIENTAL POR MEIO DE ANÁLISE GEOESPACIAL: UMA APLICAÇÃO NA ALTA BACIA DOS RIOS

PIRACICABA E SAPUCAÍ-MIRIM, APA FERNÃO DIAS, MG

DANILO TROVÓ GARÓFALO, MARCOS CÉSAR FERREIRA

Quadro 1: Variáveis geoambientais, suas justificativas de uso, métodos de elaboração e variáveis representadas em mapas temáticos.

Fonte: Autores.

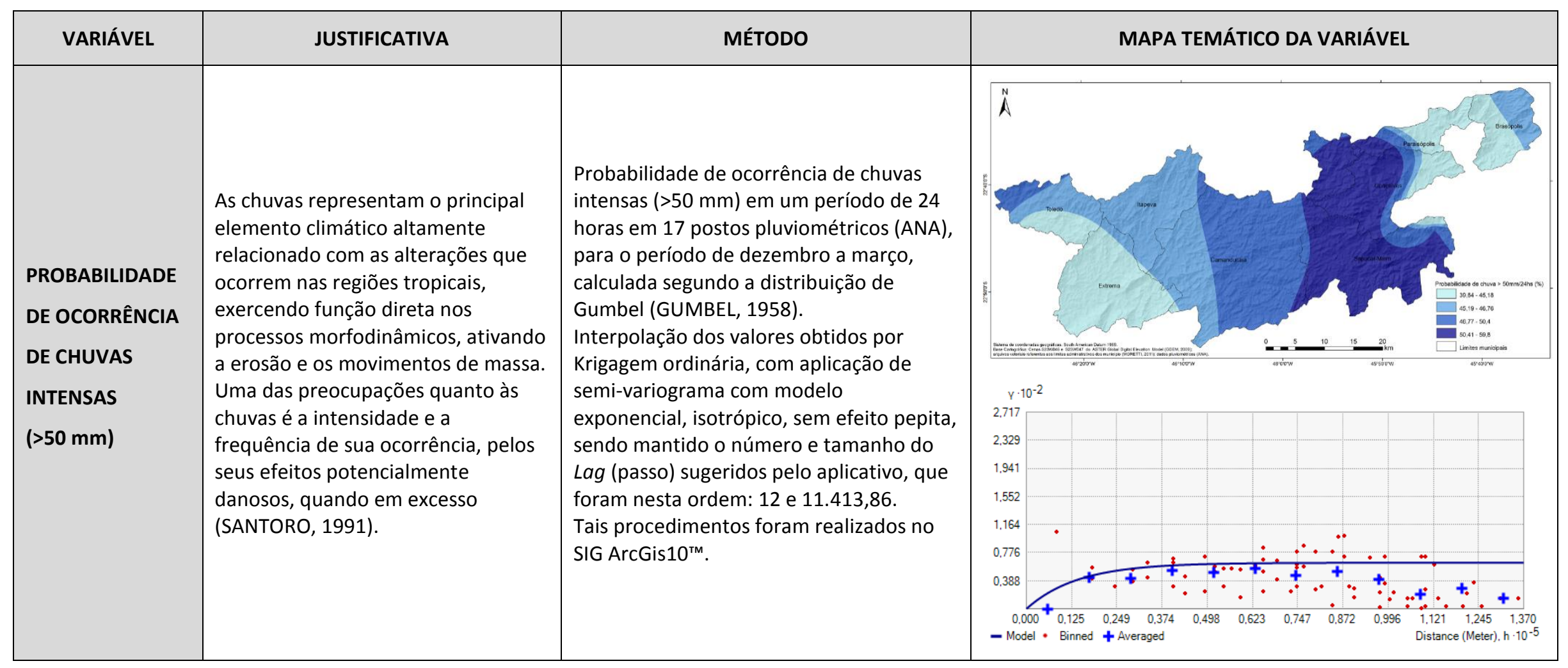


O mapeamento da distribuição espacial de processos erosivos e movimentos de massa na APA Fernão Dias tomou como base em imagens orbitais do banco de imagens do software Google Earth, uma vez que estas apresentam resolução espacial compatível ao mapeamento dos fenômenos em análise, além de serem de uso gratuito.

Para melhor identificação dos fenômenos em análise foi criada uma chave de interpretação contendo as principais características destes fenômenos observadas nas imagens no software Google Earth (Quadro 2). A chave de interpretação, conforme Avery e Berlim (1985), ajudam os foto intérpretes a identificar as características dos fenômenos na imagem e têm por base a descrição e a ilustração dos objetos de acordo com determinadas categorias.

\begin{tabular}{|c|c|c|}
\hline CLASSE & $\begin{array}{l}\text { ELEMENTOS DE } \\
\text { INTERPRETAÇÃO } \\
\text { DOS PROCESSOS }\end{array}$ & $\begin{array}{c}\text { FEIÇÕES OBSERVADAS NAS IMAGENS DISPONÍVEIS NO } \\
\text { SOFTWARE GOOGLE EARTH }\end{array}$ \\
\hline Erosão linear & $\begin{array}{l}\text { Feições lineares: } \\
\text { - Sulcos e valas } \\
\text { apresentam } \\
\text { largura até 0,5m; } \\
\text { - Ravinas } \\
\text { apresentam } \\
\text { larguras } \\
\text { superiores à } \\
\text { 0,5m. }\end{array}$ & \\
\hline Escorregamento & $\begin{array}{l}\text { Geometria variável: } \\
\text { - Planares; } \\
\text { - Circulares; } \\
\text { - Em cunha. } \\
\text { - Geralmente } \\
\text { associados à corte } \\
\text { de talude; } \\
\text { - Presença de } \\
\text { material } \\
\text { deslocado para } \\
\text { sua base; }\end{array}$ & $\stackrel{130 m}{1}$ \\
\hline
\end{tabular}

Quadro 2: Chave de interpretação visual dos processos erosivos e dos movimentos de massa. Fonte: Autores. 
Inicialmente os arquivos vetoriais em formato shape (IBGE, 2010), correspondentes aos limites territoriais da APA e aos seus respectivos municípios, foram convertidos para o formato $\mathrm{kmz}$, por meio do comando Conversion Tools, do SIG ArcGIS $10^{\text {TM }}$, sendo posteriormente exportados para o software Google Earth.

A identificação e mapeamento dos processos erosivos lineares e cicatrizes de escorregamento foram realizados diretamente no software Google Earth,em escala fixa de 1:1.500, por meio do comando "Adicionar Marcador". Após este processo, para cada município foi salva uma imagem em formato JPEG, em alta resolução (4800×2425 pixels), contendo a localização pontual dos processos identificados. Em seguida, estas imagens foram exportadas para o ArcGIS $10^{\text {TM }}$, onde foram registradas no sistema de coordenadas geográficas, segundo o datum SAD 69 (South American Datum 1969). Sobre estas imagens georreferenciadas os processos identificados foram novamente vetorizados.

Posteriormente, as variáveis geoambientais foram classificadas em quatro classes, por meio do método de classificação Quartil, e calculada a área de cada classe. O passo seguinte foi calcular as ocorrências observada e esperada de processos erosivos e os movimentos de massa para cada classe das variáveis geoambientais (Tabelas 2 a 6).

\begin{tabular}{|l|c|c|c|c|}
\hline \multirow{2}{*}{\multicolumn{1}{c|}{ PARÂMETROS ESTATÍstICOS }} & \multicolumn{4}{c|}{ CLASSES DE NDVI } \\
\cline { 2 - 5 } & $\mathbf{- 0 , 2 3}$ a 0,51 & $\mathbf{0 , 5 2}$ a 0,57 & $\mathbf{0 , 5 8}$ a 0,62 & $\mathbf{0 , 6 3}$ a 0,82 \\
\hline Área ocupada em porcentagem & 24,08 & 24,52 & 25,18 & 26,23 \\
\hline Ocorrência observada de escorregamento & 93 & 58 & 24 & 07 \\
\hline Ocorrência esperada de escorregamento & 44 & 45 & 46 & 48 \\
\hline Ocorrência observada de ravina & 430 & 170 & 99 & 30 \\
\hline Ocorrência esperada de ravina & 176 & 179 & 184 & 191 \\
\hline Ocorrência observada de todos eventos & 523 & 228 & 123 & 37 \\
\hline Ocorrência esperada de todos eventos & 219 & 223 & 229 & 239 \\
\hline
\end{tabular}

Tabela 2: Ocorrências observada e esperada de ravinas e escorregamentos, segundo intervalos de NDVI. Fonte: Autores.

\begin{tabular}{|l|c|c|c|c|}
\hline \multirow{2}{*}{\multicolumn{1}{c|}{ PARÂMETROS ESTATístICOS }} & \multicolumn{4}{c|}{ CLASSES DE DECLIVIDADE } \\
\cline { 2 - 5 } & $\mathbf{0}$ a 8,07 & $\mathbf{8 , 0 8}$ a 12,9 & $\mathbf{1 3 a} \mathbf{1 8 , 4}$ & $\mathbf{1 8 , 5}$ a 64,3 \\
\hline Área ocupada em porcentagem & $\mathbf{2 4 , 7 5}$ & $\mathbf{2 4 , 7 5}$ & $\mathbf{2 5 , 3 1}$ & $\mathbf{2 5 , 1 9}$ \\
\hline Ocorrência observada de escorregamento & 35 & 60 & 57 & 30 \\
\hline Ocorrência esperada de escorregamento & 45 & 45 & 46 & 46 \\
\hline Ocorrência observada de ravina & 113 & 215 & 236 & 165 \\
\hline Ocorrência esperada de ravina & 180 & 180 & 185 & 184 \\
\hline Ocorrência observada de todos eventos & 148 & 275 & 293 & 195 \\
\hline Ocorrência esperada de todos eventos & 225 & 225 & 231 & 230 \\
\hline
\end{tabular}

Tabela 3: Ocorrências observada e esperada de ravinas e escorregamentos, segundo intervalos de declividade. 
Fonte: Autores.

\begin{tabular}{|l|c|c|c|c|}
\hline \multirow{2}{*}{\multicolumn{1}{|c|}{ PARÂMETROS ESTATÍstICOS }} & \multicolumn{4}{c|}{ CLASSES DE POCI } \\
\cline { 2 - 5 } & $\mathbf{3 9 , 6 4}$ a 45,18 & $\mathbf{4 5 , 1 9}$ a 46,76 & $\mathbf{4 6 , 7 7}$ a 50,4 & $\mathbf{5 0 , 4 1}$ a 59,8 \\
\hline Área ocupada em porcentagem & 24,06 & 25,41 & $\mathbf{2 5 , 6 9}$ & $\mathbf{2 4 , 8 4}$ \\
\hline Ocorrência observada de escorregamento & 56 & 78 & 35 & 13 \\
\hline Ocorrência esperada de escorregamento & 44 & 46 & 47 & 45 \\
\hline Ocorrência observada de ravina & 204 & 371 & 131 & 23 \\
\hline Ocorrência esperada de ravina & 175 & 185 & 187 & 181 \\
\hline Ocorrência observada de todos eventos & 260 & 449 & 166 & 36 \\
\hline Ocorrência esperada de todos eventos & 219 & 231 & 234 & 226 \\
\hline
\end{tabular}

Tabela 4: Ocorrências observada e esperada de processos erosivos e movimentos de massa, segundo intervalos de $\mathrm{POCl}$.

Fonte: Autores.

\begin{tabular}{|l|r|r|r|c|}
\hline \multirow{2}{*}{\multicolumn{1}{c|}{ PARÂMETROS ESTATÍ́stICOS }} & \multicolumn{4}{c|}{ CLASSES DE DENSIDADE DE LINEAMENTOS (KM/KM $\mathbf{2}^{\mathbf{}}$ ) } \\
\cline { 2 - 5 } & $\mathbf{0}$ a $\mathbf{0 , 4 7}$ & $\mathbf{0 , 4 8}$ a 0,6 & $\mathbf{0 , 6 1}$ a 0,73 & $\mathbf{0 , 7 4}$ a 1,3 \\
\hline Área ocupada em porcentagem & 24,81 & 25,35 & $\mathbf{2 4 , 8 4}$ & $\mathbf{2 4 , 9 9}$ \\
\hline Ocorrência observada de escorregamento & 29 & 51 & 38 & 64 \\
\hline Ocorrência esperada de escorregamento & 45 & 46 & 45 & 45 \\
\hline Ocorrência observada de ravina & 140 & 185 & 179 & 225 \\
\hline Ocorrência esperada de ravina & 181 & 185 & 181 & 182 \\
\hline Ocorrência observada de todos eventos & 169 & 236 & 217 & 289 \\
\hline Ocorrência de todos eventos esperada & 226 & 231 & 227 & 227 \\
\hline
\end{tabular}

Tabela 5: Ocorrências observada e esperada de processos erosivos e movimentos de massa, segundo intervalos de densidade de lineamentos estruturais.

Fonte: Autores.

\begin{tabular}{|l|c|c|c|c|}
\hline \multirow{2}{*}{\multicolumn{1}{c|}{ PARÂMETROS ESTATÍstICOS }} & \multicolumn{4}{c|}{ CLASSES DE NDVI } \\
\cline { 2 - 5 } & $\mathbf{- 0 , 2 3}$ a 0,51 & $\mathbf{0 , 5 2}$ a 0,57 & $\mathbf{0 , 5 8}$ a 0,62 & $\mathbf{0 , 6 3}$ a 0,82 \\
\hline Área ocupada em porcentagem & 24,48 & 24,85 & $\mathbf{2 5 , 6 8}$ & $\mathbf{2 4 , 9 8}$ \\
\hline Ocorrência de escorregamento & 20 & 54 & 50 & 58 \\
\hline Ocorrência esperada de escorregamento & 45 & 45 & 47 & 45 \\
\hline Ocorrência de ravina & 106 & 177 & 246 & 200 \\
\hline Ocorrência esperada de ravina & 178 & 181 & 187 & 182 \\
\hline Ocorrência de todos eventos & 126 & 231 & 296 & 258 \\
\hline Ocorrência esperada de todos eventos & 224 & 226 & 234 & 227 \\
\hline
\end{tabular}

Tabela 6: Ocorrências observada e esperada de processos erosivos e movimentos de massa, segundo intervalos de densidade de vias de circulação.

Fonte: Autores.

As tabelas 2, 3, 4, 5 e 6, apresentam a área ocupada por classe de variáveis geoambientais, quantidades de processos erosivos e de movimentos de massa mapeados. Estes dados permitiram calculara frequência observada e a frequência esperada dos processos por classe de variável ambiental. Se a variável ambiental não possuir qualquer influência sobre a ocorrência de processos erosivos e movimentos de massa, são esperadas frequências proporcionais às áreas das classes Contudo, por se tratar de dados aleatórios, não é esperada uma correspondência exata, e, por isso é verificado se as diferenças nos valores da ocorrência observada e da ocorrência 
esperada são significativas (Ferreira, 2014). Para tanto, aplicou-se o Teste Estatístico Kolmogorov-Smirnov (Teste EKS), conforme proposto por Taylor (1977):

$H_{0}$ indica que as variáveis geoambientais não influenciam a ocorrência de processos erosivos e movimentos de massa.

O nível de significância é $\alpha=0,05$.

As frequências observadas $\left(\mathrm{O}_{\mathrm{i}}\right)$ e esperadas $\left(\mathrm{E}_{\mathrm{i}}\right)$ são calculadas em proporções cumulativas, listando suas diferenças com o emprego da estatística $D$ :

- $D=\operatorname{Max}\left|O_{i}-E_{i}\right|[$ eq. 1]

Os valores críticos de $D$ para amostras com mais de 35 indivíduos a um nível de significância de $\alpha=0,05$ são dados por:

- $D(\alpha=0,05)=\frac{1,36}{\sqrt{n}}[$ eq. 2$]$

Desta forma, caso o valor encontrado de $D$ seja maior ou igual ao seu valor crítico a um nível de significância de $\alpha=0,05$, conclui-se que a variável geoambiental tem influência na ocorrência de processos erosivos e movimentos de massa, e a hipótese nula é rejeitada. Caso contrário, a hipótese nula é aceita. Os resultados do Teste EKS aplicado às variáveis geoambientais são apresentados nas Tabelas 7, 8, 9, 10 e 11.

Assumimos que quanto maior o valor de $D$ em relação ao $D$-crítico, maior será a influência da respectiva variável na ocorrência dos processos. Desta forma, o maior valor encontrado de $D$ para dada variável geoambiental foi definido como sendo o peso desta à ocorrência de processos erosivos e movimentos de massa. A fim de padronizar a escala de valores referentes ao peso das variáveis geoambientais, os valores apresentados nas tabelas 7, 8, 9, 10 e 11, foram convertidos para a escala 0,0 1,0 (Tabela 12). 
DANILO TROVÓ GARÓFALO, MARCOS CÉSAR FERREIRA

\begin{tabular}{|c|c|c|c|c|c|c|}
\hline \multirow{2}{*}{ FENÔMENO } & \multirow{2}{*}{$\begin{array}{l}\text { PARÂMETROS } \\
\text { ESTATÍSTICOS }\end{array}$} & \multicolumn{4}{|c|}{ CLASSES DE NDVI } & \multirow{2}{*}{ D CRÍTICO } \\
\hline & & $-0,23$ a 0,51 & 0,52 a 0,57 & 0,58 a 0,62 & 0,63 a 0,82 & \\
\hline \multirow{5}{*}{ 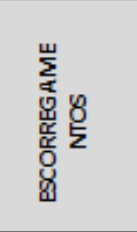 } & Frequência observada & 0,511 & 0,319 & 0,132 & 0,038 & \multirow{5}{*}{0,101} \\
\hline & Frequência esperada & 0,241 & 0,245 & 0,252 & 0,262 & \\
\hline & $\begin{array}{l}\text { Freq. acumulada } \\
\text { observada }\end{array}$ & 0,511 & 0,830 & 0,962 & 1,000 & \\
\hline & $\begin{array}{l}\text { Freq. acumulada } \\
\text { esperada }\end{array}$ & 0,241 & 0,486 & 0,738 & 1,000 & \\
\hline & Diferenças $(\mathrm{O}-\mathrm{E})$ & 0,270 & 0,344 & 0,224 & 0,000 & \\
\hline \multirow{5}{*}{ 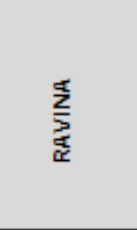 } & Frequência observada & 0,590 & 0,233 & 0,136 & 0,041 & \multirow{5}{*}{0,051} \\
\hline & Frequência esperada & 0,241 & 0,245 & 0,252 & 0,262 & \\
\hline & $\begin{array}{l}\text { Freq. acumulada } \\
\text { observada }\end{array}$ & 0,590 & 0,823 & 0,959 & 1,000 & \\
\hline & $\begin{array}{l}\text { Freq. acumulada } \\
\text { esperada }\end{array}$ & 0,241 & 0,486 & 0,738 & 1,000 & \\
\hline & Diferenças $(\mathrm{O}-\mathrm{E})$ & 0,349 & 0,337 & 0,221 & 0,000 & \\
\hline \multirow{5}{*}{ 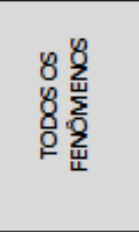 } & Frequência observada & 0,574 & 0,250 & 0,135 & 0,041 & \multirow{5}{*}{0,045} \\
\hline & Frequência esperada & 0,241 & 0,245 & 0,252 & 0,262 & \\
\hline & $\begin{array}{l}\text { Freq. acumulada } \\
\text { observada }\end{array}$ & 0,574 & 0,824 & 0,959 & 1,000 & \\
\hline & $\begin{array}{l}\text { Freq. acumulada } \\
\text { esperada }\end{array}$ & 0,241 & 0,486 & 0,738 & 1,000 & \\
\hline & Diferenças $(\mathrm{O}-\mathrm{E})$ & 0,333 & 0,338 & 0,222 & 0,000 & \\
\hline
\end{tabular}

Tabela 7: Resultados da aplicação do teste estatístico Kolmogorov-Smirnov ao índice de vegetação.

\begin{tabular}{|c|c|c|c|c|c|c|}
\hline \multirow{2}{*}{ FENÔMENO } & \multirow{2}{*}{$\begin{array}{l}\text { PARÂMETROS } \\
\text { ESTATÍSTICOS }\end{array}$} & \multicolumn{4}{|c|}{ CLASSES DE DECLIVIDADE } & \multirow{2}{*}{ D CRítICO } \\
\hline & & 0 a 8,07 & 8,08 a 12,9 & 13 a 18,4 & 18,5 a 64,3 & \\
\hline \multirow{5}{*}{ 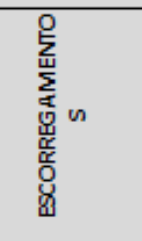 } & Frequência observada & 0,192 & 0,330 & 0,313 & 0,165 & \multirow{5}{*}{0,096} \\
\hline & Frequência esperada & 0,247 & 0,248 & 0,253 & 0,252 & \\
\hline & $\begin{array}{l}\text { Freq. acumulada } \\
\text { observada }\end{array}$ & 0,192 & 0,522 & 0,835 & 1,000 & \\
\hline & $\begin{array}{l}\text { Freq. acumulada } \\
\text { esperada }\end{array}$ & 0,247 & 0,495 & 0,748 & 1,000 & \\
\hline & Diferenças $(\mathrm{O}-\mathrm{E})$ & 0,055 & 0,027 & 0,087 & 0,000 & \\
\hline \multirow{5}{*}{ 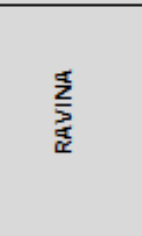 } & Frequência observada & 0,155 & 0,295 & 0,324 & 0,226 & \multirow{5}{*}{0,051} \\
\hline & Frequência esperada & 0,247 & 0,248 & 0,253 & 0,252 & \\
\hline & $\begin{array}{l}\text { Freq. acumulada } \\
\text { observada }\end{array}$ & 0,155 & 0,450 & 0,774 & 1,000 & \\
\hline & $\begin{array}{l}\text { Freq. acumulada } \\
\text { esperada }\end{array}$ & 0,247 & 0,495 & 0,748 & 1,000 & \\
\hline & Diferenças $(\mathrm{O}-\mathrm{E})$ & 0,092 & 0,045 & 0,026 & 0,000 & \\
\hline \multirow{5}{*}{ 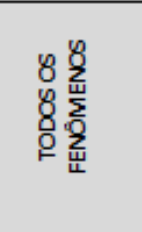 } & Frequência observada & 0,155 & 0,295 & 0,324 & 0,226 & \multirow{5}{*}{0,045} \\
\hline & Frequência esperada & 0,247 & 0,247 & 0,254 & 0,252 & \\
\hline & $\begin{array}{l}\text { Freq. acumulada } \\
\text { observada }\end{array}$ & 0,155 & 0,450 & 0,774 & 1,000 & \\
\hline & $\begin{array}{l}\text { Freq. acumulada } \\
\text { esperada }\end{array}$ & 0,247 & 0,494 & 0,748 & 1,000 & \\
\hline & Diferenças $(\mathrm{O}-\mathrm{E})$ & 0,092 & 0,044 & 0,026 & 0,000 & \\
\hline
\end{tabular}

Tabela 8: Resultados da aplicação do teste estatístico Kolmogorov-Smirnov à variável declividade. 
DANILO TROVÓ GARÓFALO, MARCOS CÉSAR FERREIRA

\begin{tabular}{|c|c|c|c|c|c|c|}
\hline \multirow{2}{*}{ FENÔMENO } & \multirow{2}{*}{$\begin{array}{l}\text { PARÂMETROS } \\
\text { ESTATÍSTICOS }\end{array}$} & \multicolumn{4}{|c|}{ CLASSES DE POCI } & \multirow{2}{*}{ D CRÍTICO } \\
\hline & & 39,64 a 45,18 & 45,19 a 46,76 & 46,77 a 50,4 & 50,41 a 59,8 & \\
\hline \multirow{5}{*}{ 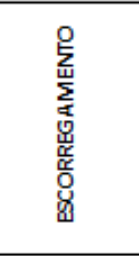 } & $\begin{array}{r}\text { Frequência } \\
\text { observada }\end{array}$ & 0,310 & 0,430 & 0,190 & 0,070 & \multirow{5}{*}{0,1008} \\
\hline & Frequência esperada & 0,240 & 0,250 & 0,260 & 0,250 & \\
\hline & $\begin{array}{r}\text { Freq. acumulada } \\
\text { observada }\end{array}$ & 0,310 & 0,740 & 0,930 & 1,000 & \\
\hline & $\begin{array}{r}\begin{array}{r}\text { Freq. acumulada } \\
\text { esperada }\end{array} \\
\end{array}$ & 0,240 & 0,490 & 0,750 & 1,000 & \\
\hline & Diferenças $(\mathrm{O}-\mathrm{E})$ & 0,067 & 0,242 & 0,177 & 0,000 & \\
\hline \multirow{5}{*}{ 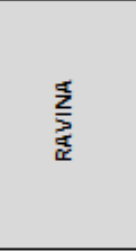 } & $\begin{array}{r}\text { Frequência } \\
\text { observada } \\
\end{array}$ & 0,280 & 0,509 & 0,180 & 0,032 & \multirow{5}{*}{0,051} \\
\hline & Frequência esperada & 0,241 & 0,254 & 0,257 & 0,248 & \\
\hline & $\begin{array}{r}\text { Freq. acumulada } \\
\text { observada }\end{array}$ & 0,280 & 0,789 & 0,968 & 1,000 & \\
\hline & $\begin{array}{r}\text { Freq. acumulada } \\
\text { esperada }\end{array}$ & 0,241 & 0,495 & 0,752 & 1,000 & \\
\hline & Diferenças $(\mathrm{O}-\mathrm{E})$ & 0,039 & 0,294 & 0,217 & 0,000 & \\
\hline \multirow{5}{*}{$\begin{array}{l}8 \\
8 \\
8 \text { 离 } \\
8 \\
8 \sum^{4}\end{array}$} & $\begin{array}{r}\text { Frequência } \\
\text { observada } \\
\end{array}$ & 0,285 & 0,493 & 0,182 & 0,040 & \multirow{5}{*}{0,045} \\
\hline & Frequência esperada & 0,241 & 0,254 & 0,257 & 0,248 & \\
\hline & $\begin{array}{r}\text { Freq. acumulada } \\
\text { observada }\end{array}$ & 0,285 & 0,778 & 0,961 & 1,000 & \\
\hline & $\begin{array}{r}\begin{array}{r}\text { Freq. acumulada } \\
\text { esperada }\end{array} \\
\end{array}$ & 0,241 & 0,495 & 0,752 & 1,000 & \\
\hline & Diferenças $(\mathrm{O}-\mathrm{E})$ & 0,045 & 0,284 & 0,209 & 0,000 & \\
\hline
\end{tabular}

Tabela 9: Resultados da aplicação do teste estatístico Kolmogorov-Smirnov à variável precipitação.

\begin{tabular}{|c|c|c|c|c|c|c|}
\hline \multirow{2}{*}{ FENÔMENO } & \multirow{2}{*}{$\begin{array}{l}\text { PARÂMETROS } \\
\text { ESTATÍSTICOS }\end{array}$} & \multicolumn{4}{|c|}{ CLASSES DE DENSIDADE DE LINEAMENTOS (KM/KM $\left.{ }^{2}\right)$} & \multirow{2}{*}{ D CRÍtico } \\
\hline & & 0 a 0,47 & 0,48 a 0,6 & 0,61 a 0,73 & 0,74 a 1,3 & \\
\hline \multirow{5}{*}{ 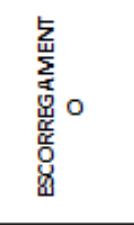 } & Frequência observada & 0,160 & 0,280 & 0,210 & 0,350 & \multirow{5}{*}{0,101} \\
\hline & Frequência esperada & 0,250 & 0,250 & 0,250 & 0,250 & \\
\hline & $\begin{array}{l}\text { Freq. acumulada } \\
\text { observada }\end{array}$ & 0,160 & 0,440 & 0,650 & 1,000 & \\
\hline & $\begin{array}{l}\text { Freq. acumulada } \\
\text { esperada }\end{array}$ & 0,250 & 0,500 & 0,750 & 1,000 & \\
\hline & Diferenças $(\mathrm{O}-\mathrm{E})$ & 0,089 & 0,062 & 0,102 & 0,000 & \\
\hline \multirow{5}{*}{ 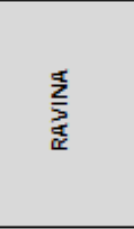 } & Frequência observada & 0,192 & 0,254 & 0,246 & 0,309 & \multirow{5}{*}{0,051} \\
\hline & Frequência esperada & 0,248 & 0,254 & 0,248 & 0,250 & \\
\hline & $\begin{array}{ll}\begin{array}{l}\text { Freq. } \\
\text { observada }\end{array} & \text { acumulada } \\
\end{array}$ & 0,192 & 0,446 & 0,691 & 1,000 & \\
\hline & $\begin{array}{ll}\begin{array}{l}\text { Freq. } \\
\text { esperada }\end{array} & \text { acumulada } \\
\end{array}$ & 0,248 & 0,502 & 0,750 & 1,000 & \\
\hline & Diferenças $(\mathrm{O}-\mathrm{E})$ & 0,056 & 0,056 & 0,059 & 0,000 & \\
\hline \multirow{5}{*}{ 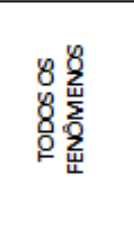 } & Frequência observada & 0,186 & 0,259 & 0,238 & 0,317 & \multirow{5}{*}{0,045} \\
\hline & Frequência esperada & 0,248 & 0,254 & 0,248 & 0,250 & \\
\hline & $\begin{array}{ll}\begin{array}{l}\text { Freq. } \\
\text { observada }\end{array} & \text { acumulada } \\
\end{array}$ & 0,186 & 0,445 & 0,683 & 1,000 & \\
\hline & $\begin{array}{ll}\begin{array}{l}\text { Freq. } \\
\text { esperada }\end{array} & \text { acumulada } \\
\end{array}$ & 0,248 & 0,502 & 0,750 & 1,000 & \\
\hline & Diferenças $(\mathrm{O}-\mathrm{E})$ & 0,063 & 0,057 & 0,067 & 0,000 & \\
\hline
\end{tabular}

Tabela 10: Resultados da aplicação do teste estatístico Kolmogorov-Smirnov ao lineamento estrutural. 


\begin{tabular}{|c|c|c|c|c|c|c|}
\hline \multirow{2}{*}{ FENÔMENO } & \multirow{2}{*}{$\begin{array}{l}\text { PARÂMETROS } \\
\text { ESTATISTIICOS }\end{array}$} & \multicolumn{4}{|c|}{ CLASSES DE DENSIDADE DE ESTRADAS } & \multirow{2}{*}{ D CRÍTICO } \\
\hline & & 0 a 1,2 & 1,3 a 1,7 & 1,8 a 2,3 & 2,4 a 4,6 & \\
\hline \multirow{5}{*}{ 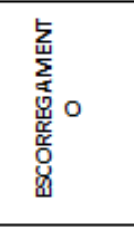 } & Frequência observada & 0,112 & 0,303 & 0,281 & 0,326 & \multirow{5}{*}{0,101} \\
\hline & Frequência esperada & 0,250 & 0,254 & 0,263 & 0,255 & \\
\hline & $\begin{array}{l}\text { Freq. acumulada } \\
\text { observada }\end{array}$ & 0,112 & 0,416 & 0,697 & 1,022 & \\
\hline & $\begin{array}{l}\text { Freq. acumulada } \\
\text { esperada }\end{array}$ & 0,250 & 0,504 & 0,767 & 1,022 & \\
\hline & Diferenças $(\mathrm{O}-\mathrm{E})$ & 0,138 & 0,089 & 0,070 & 0,000 & \\
\hline \multirow{5}{*}{ 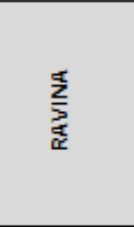 } & Frequência observada & 0,145 & 0,243 & 0,337 & 0,274 & \multirow{5}{*}{0,051} \\
\hline & Frequência esperada & 0,245 & 0,249 & 0,257 & 0,250 & \\
\hline & $\begin{array}{l}\text { Freq. acumulada } \\
\text { observada }\end{array}$ & 0,145 & 0,388 & 0,726 & 1,000 & \\
\hline & $\begin{array}{l}\text { Freq. acumulada } \\
\text { esperada }\end{array}$ & 0,245 & 0,493 & 0,750 & 1,000 & \\
\hline & Diferenças $(\mathrm{O}-\mathrm{E})$ & 0,099 & 0,105 & 0,025 & 0,000 & \\
\hline \multirow{5}{*}{ 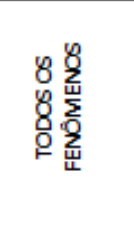 } & Frequência observada & 0,138 & 0,254 & 0,325 & 0,283 & \multirow{5}{*}{0,045} \\
\hline & Frequência esperada & 0,245 & 0,249 & 0,257 & 0,250 & \\
\hline & $\begin{array}{l}\text { Freq. acumulada } \\
\text { observada }\end{array}$ & 0,138 & 0,392 & 0,717 & 1,000 & \\
\hline & $\begin{array}{l}\text { Freq. acumulada } \\
\text { esperada }\end{array}$ & 0,245 & 0,493 & 0,750 & 1,000 & \\
\hline & Diferenças $(\mathrm{O}-\mathrm{E})$ & 0,107 & 0,102 & 0,033 & 0,000 & \\
\hline
\end{tabular}

Tabela 11: Resultados da aplicação do teste estatístico Kolmogorov-Smirnov às vias de circulação.

\begin{tabular}{|l|r|r|r|r|r|}
\hline \multirow{2}{*}{ PROCESSO GERADO } & \multicolumn{5}{|c|}{ PESO DAS VARIÁVEIS AMBIENTAIS INFLUENCIADORAS } \\
\cline { 2 - 6 } & $\begin{array}{c}\text { DENSIDADE } \\
\text { DE ESTRADAS }\end{array}$ & $\begin{array}{c}\text { DENSIDADE } \\
\text { DE LINEAMENTOS }\end{array}$ & DECLIVIDADE & \multicolumn{1}{c|}{ POCI } & \multicolumn{1}{c|}{ NDVI } \\
\hline ESCORREGAMENTOS & 0,151 & 0,112 & 0,095 & 0,265 & 0,377 \\
\hline RAVINAS & 0,118 & 0,067 & 0,104 & 0,331 & 0,380 \\
\hline TODOS PROCESSOS & 0,120 & 0,075 & 0,104 & 0,320 & 0,381 \\
\hline
\end{tabular}

Tabela 12: Valores dos pesos normalizados das variáveis geoambientais.

A análise integrada das variáveis geoambientais de um sistema, por meio de mapas temáticos representados em campos contínuos,necessita que estes estejam em uma mesma escala de valores. Para tanto, é necessário que seja feita uma padronização destes valores. Uma forma de se obter esta padronização é por meio da Lógica Fuzzy. A teoria do conjunto fuzzy, apresentada por Zadeh (1965), é uma ampliação da teoria convencional de conjuntos e sua utilização é apropriada em sistemas que se caracterizam pela generalidade, ambiguidade e imprecisão (FUKS, 1998). Enquanto os conjuntos tratados pela lógica booleana permitem apenas o uso de funções de associação binária ( $\left.\begin{array}{lll}0 & \text { e } & 1\end{array}\right)$, que identificam os elementos pertencentes ou não pertencentes a uma classe, a lógica fuzzy admite também a possibilidade de uma associação parcial, ou seja, elementos que são parcialmente pertencentes a uma ou mais classes (entre 0 e 1) (FUKS, 1998).

A forma como os valores são atribuídos à classificação contínua depende da função de pertinência, ou seja, a função que associa a cada elemento um valor no intervalo contínuo entre 0 e 1 (SILVA, 2003, FERREIRA, 2014). Silva (2003) ressalta que a função 
de pertinência pode ser modelada através de classes naturais e por imposição de classe. Ainda de acordo com Silva (op. cit.), "o modelo por classes naturais avalia a distribuição natural das observações, dentro de um campo multivariado estável, naturalmente ocorrendo em grupo", enquanto que "a função de pertinência gerada pelo modelo tipo imposição de classes se dá pela especificação dos limites da classe, baseados em experiências ou definições impostas". Desta forma, a partir dos limites inferiores e superiores são definidas as funções: lineares, gaussianas, sigmoidais, polinomiais, entre outras.

No contexto desta pesquisa, utilizamos a função de pertinência linear para a padronização das variáveis geoambientais. A função linear define uma função de pertinência fuzzy através de uma transformação linear baseada em uma reta, entre o valor mínimo especificado, com atribuição de 0 (zero), para o valor máxima definido, com atribuição de 1 (um) (ESRI, 2010).

Foi definido como máximo o maior valor observado em cada uma das variáveis geoambientais, e, como mínimo o menor valor observado. Com relação à cobertura vegetal adotou-se procedimento inverso, isto é, foi definido como máximo o menor valor de NDVI, e como mínimo, o maior valor de NDVI, pois as áreas mais críticas à fragilidade ambiental seriam aquelas que apresentam baixo índice de vegetação.

Definidos os pesos das variáveis geoambientais em relação à ocorrência de processos erosivos e movimentos de massa, e reescalonadas as variáveis em uma mesma escala de valores, o passo seguinte para geração dos mapas de fragilidade ambiental é a álgebra ponderada de mapas destas variáveis, de acordo com o peso de cada uma delas (equação 3):

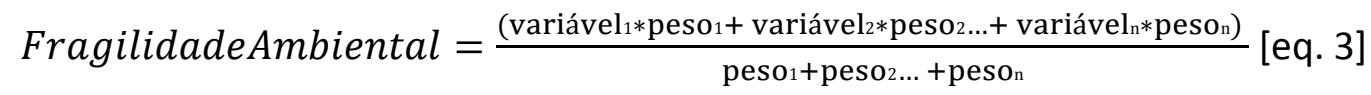




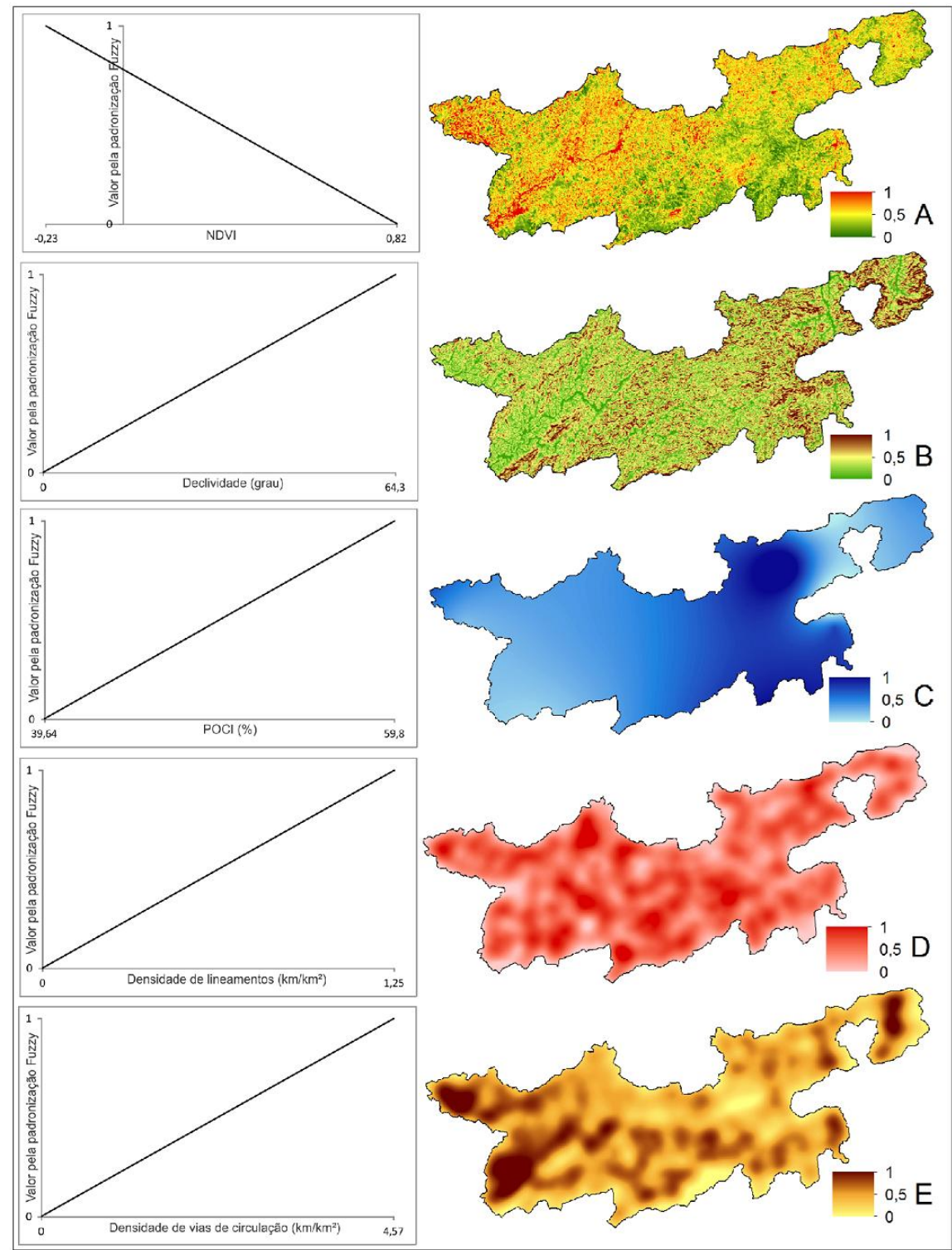

Figura 2: Gráficos das funções de pertinência fuzzy para cada uma das Variáveis e seus respectivos mapas temáticos representados em conjunto fuzzy.

\section{RESULTADOS E DISCUSSÃO}

O mapa de fragilidade ambiental à ocorrência de escorregamentos (Figura 3) mostra que as áreas mais suscetíveis a este tipo de processo apresentam baixa densidade de vegetação, alta probabilidade de ocorrência de chuvas intensas e densidade elevada de vias de circulação e lineamentos estruturais (Quadro 1). Contudo, houve pouca associação entre a ocorrência de escorregamentos e a variável declividade; a maior ocorrência deste processo se deu no intervalo de $8^{\circ}$ a $18^{\circ}$, sendo que, o valor da ocorrência observada foi muito próximo ao da ocorrência esperada (Tabela 8). Neste 
caso, a baixa ocorrência de escorregamento em vertentes de maior declividade, se deveu, em parte, aos litossolos. Nestas áreas a cobertura vegetal predominante consiste basicamente de gramíneas e arbustos, gerando área mais estáveis a escorregamentos. Isto se deve a reduzida capacidade de retenção de água bem como do menor aporte dos componentes solo e vegetação (PENTEADO; 1974). As áreas de alta fragilidade ambiental à ocorrência de escorregamentos estão localizadas na porção central da APA, em alguns trechos da porção oeste e no corredor da rodovia Fernão Dias. As bacias que apresentam maiores áreas com alta fragilidade a este processo são as do ribeirão do Juncal, do rio Capivari e do ribeirão do Paiol (Figura 3), sendo que $65,4 \%$ das cicatrizes de escorregamento identificadas estão localizadas em áreas com valores fuzzy de fragilidade ambiental maior ou igual ao valor médio de 0,339 .

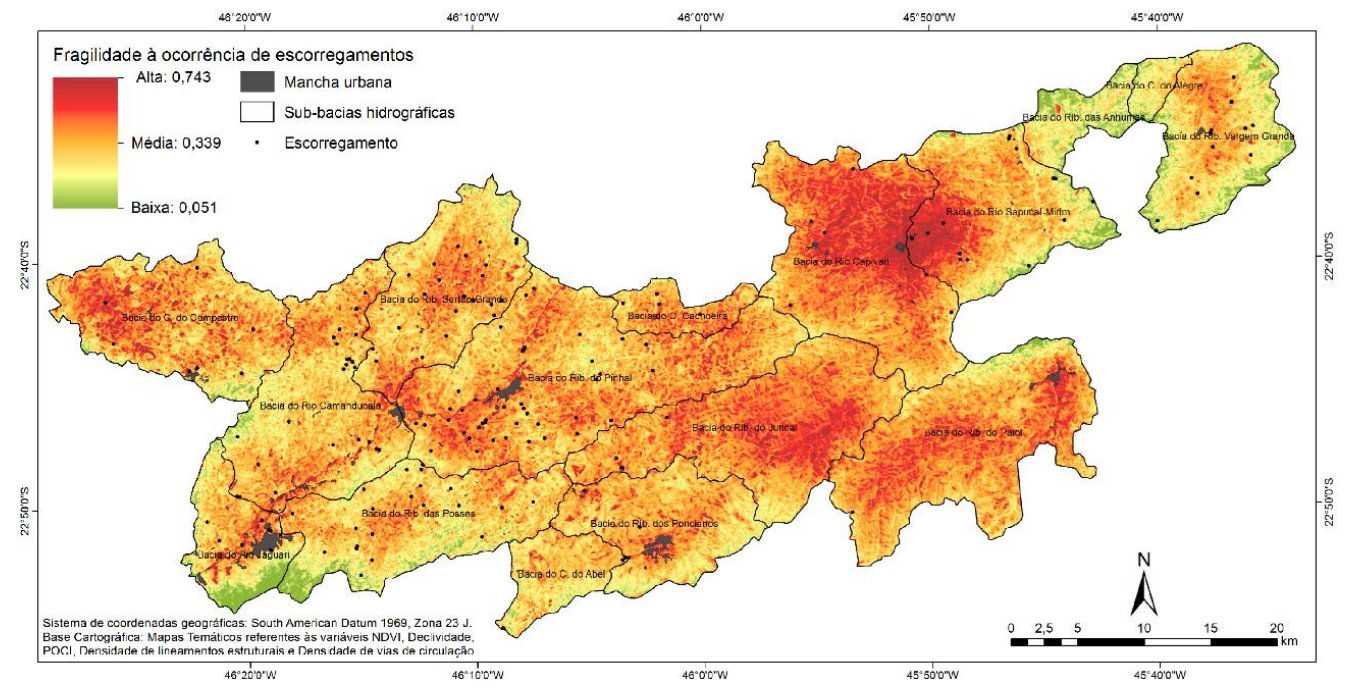

Figura 3: Mapa de fragilidade ambiental à ocorrência de escorregamento.

Observa-se no mapa de fragilidade ambiental à ocorrência de ravina (Figura 4), que as áreas mais frágeis possuem baixo índice de vegetação, vertentes íngremes, alta probabilidade de chuvas intensas, alta densidade de vias de circulação e de lineamentos estruturais (Quadro 1).

Em áreas desmatadas a ação das chuvas ocorre imediatamente, promovendo a erosão (BIGARELLA, 2007). Além disto, as vias de circulação aceleram o escoamento pluvial, intensificando os processos erosivos e o transporte de sedimentos (FORMAN e ALEXANDER, 1998); os lineamentos estruturais são apontados como aspectos 
predisponentes à ocorrência de processos erosivos lineares por constituírem importantes descontinuidades mecânicas e hidráulicas (MURATORI, 1983).As áreas com maior fragilidade ambiental à ocorrência de ravina são aquelas localizadas na porção norte da APA, na bacia hidrográfica do rio Capivari, e, na porção sudeste, bacias hidrográficas do ribeirão do Juncal e do ribeirão do Paiol. Nestas bacias o uso do solo se caracteriza por áreas agropastoris entremeadas por fragmentos florestais e sobre vertentes com declividades entre $10^{\circ}$ a $20^{\circ}$. As áreas menos suscetíveis estão localizadas na porção sudoeste da APA -bacias hidrográficas do rio Jaguari e do ribeirão das Posses, e na porção nordeste - bacias hidrográficas do ribeirão dos Anhumas e do córrego do Alegre, onde são observados remanescentes florestais significativos.Do total de 729 processos erosivos identificados, 458 (63 \%) estão localizados em áreas com valores fuzzy de fragilidade ambiental ao valor médio de 0,334 .

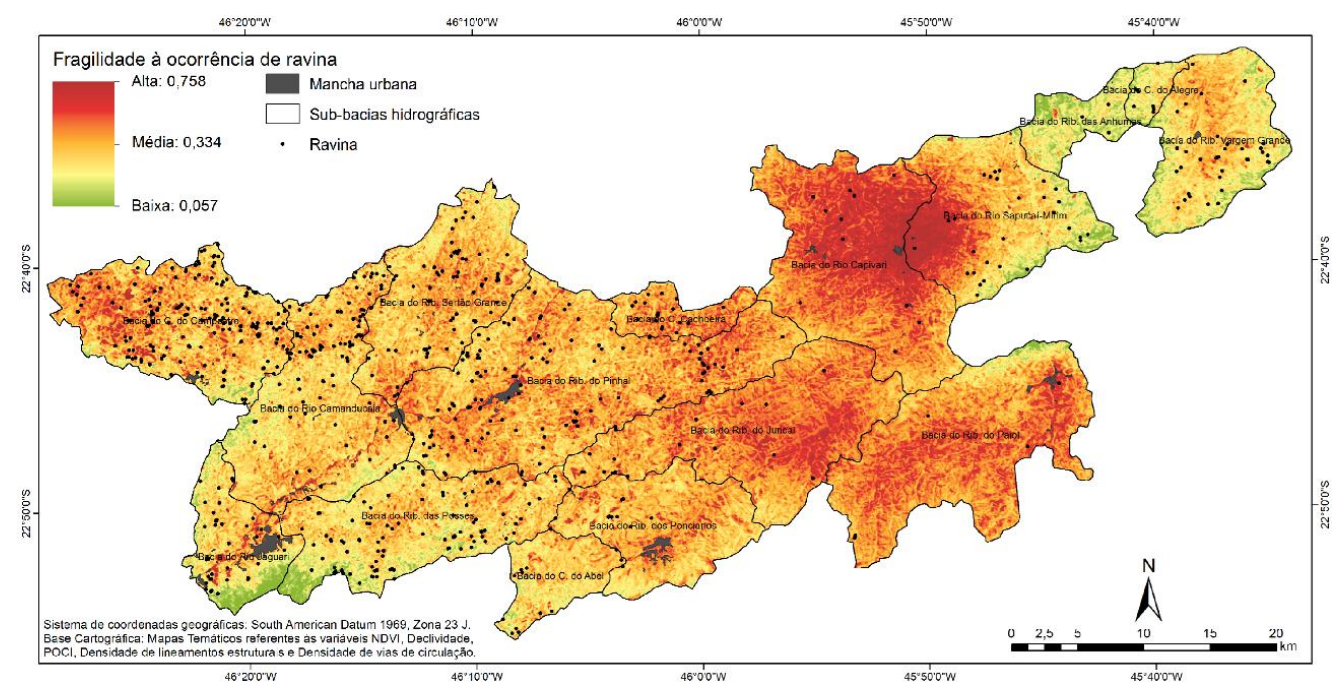

Figura 4: Mapa de fragilidade ambiental à ocorrência de ravina.

O mapa de fragilidade ambiental à ocorrência de processos erosivos e movimentos de massa (Figura 5) evidencia que, no contexto da APA Fernão Dias, as variáveis geoambientais que mais influenciam na ocorrência dos processos são, respectivamente: cobertura vegetal, chuvas intensas, declividade e densidade de estradas. Verificou-se que as áreas mais suscetíveis à ocorrência de processos erosivos e movimentos de massa são aquelas em que há a combinação entre baixo índice de vegetação, $\mathrm{POCl}$ elevada, alta densidade de vias de circulação, declividade acentuada e elevada densidade de lineamentos estruturais. 


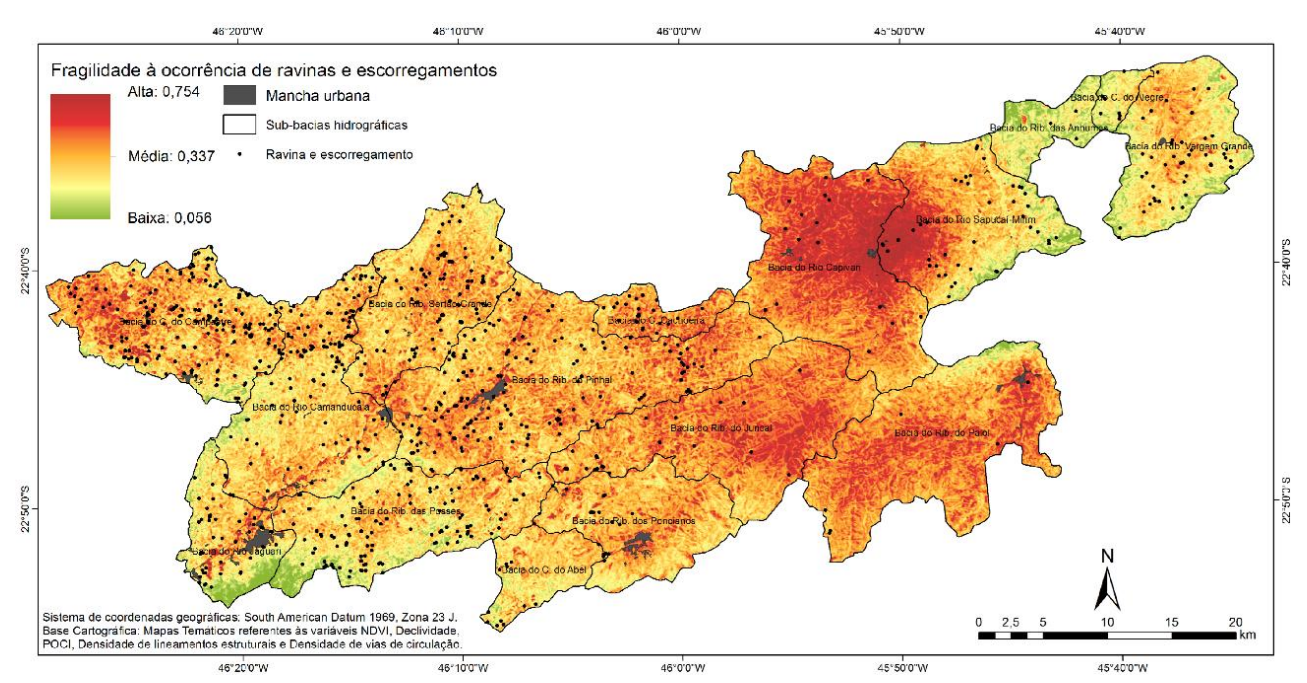

Figura 5: Mapa de fragilidade ambiental à ocorrência de processos erosivos e movimentos de massa.

Com o propósito de auxiliar a análise da fragilidade ambiental no contexto da APA Fernão Dias, como um todo, foram destacadas no mapa (Figura 6), em cor vermelha, as áreas com valores de fragilidade ambiental igual ou acima do valor fuzzy médio observado (0,337). Posteriormente foram calculados os seguintes parâmetros para cada sub-bacia: porcentagem da área de valores fuzzy acima da média; porcentagem da área das classes de uso mais significativas; densidade populacional; densidade de processos; porcentagem da área da bacia destinada às zonas de manejo; e POCI.

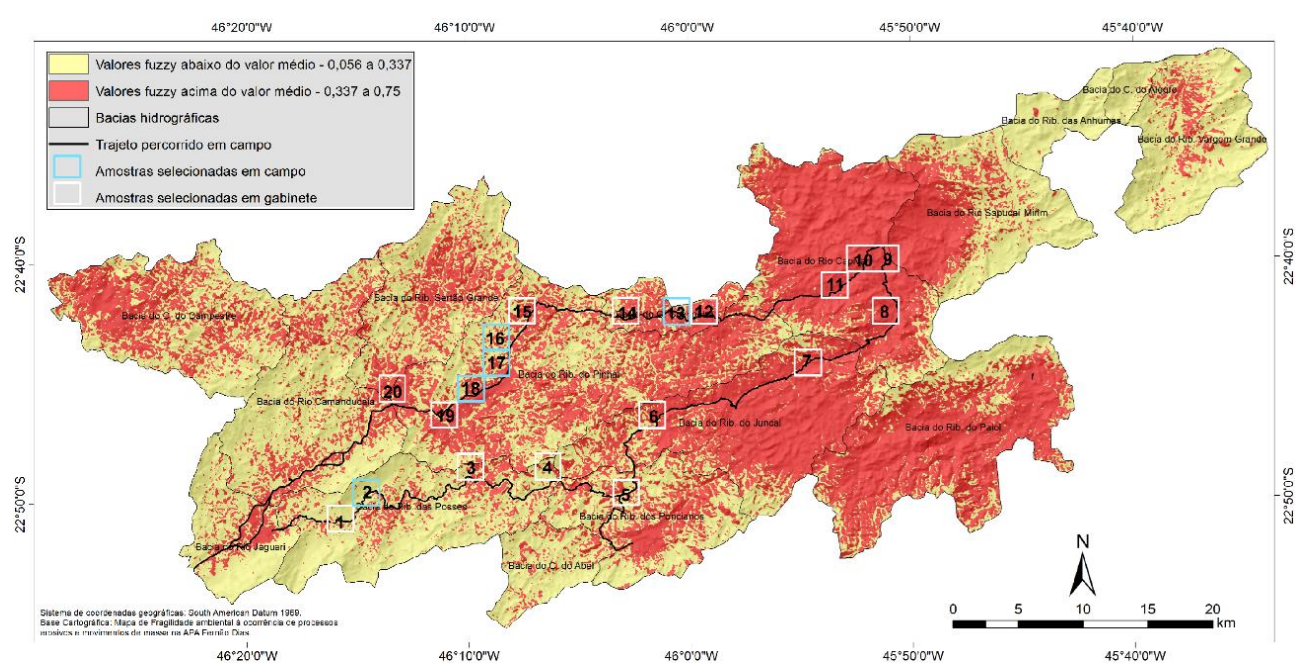

Figura 6: Áreas com valores de fragilidade ambiental $\geq$ ao valor médio de 0,4 e trajeto percorrido no trabalho de campo e áreas analisadas.

Verificou-se que as bacias hidrográficas da porção centro-leste são as que apresentam maior fragilidade, mesmo apresentando remanescentes florestais significativos. Contudo, de acordo com o zoneamento ambiental da APA, está previsto para estas bacias o uso exclusivamente agropastoril e de silvicultura, o que pode tornar a área 
ainda mais suscetível a processos erosivos e movimentos de massa. Embora estas bacias apresentem as maiores proporções de áreas classificadas como média à alta fragilidade, as densidades de processos erosivos apresentadas por elas são próximas ao valor de densidade média das bacias da APA $-1,04$ processo $/ \mathrm{km}^{2}$. Isto se deve ao fato destas bacias ainda manterem significativos remanescentes florestais, protegendo o solo da ocorrência desses processos, mesmo sendo uma área de alta probabilidade de chuvas intensas (Quadro 1).

Vale ressaltar que a bacia do ribeirão do Juncal, com 78,59 \% de sua área com valores fuzzy de fragilidade acima da média, concentra as nascentes dos rios Jaguari e Atibaia, formadores do rio Piracicaba, responsáveis por parte do abastecimento da região metropolitana da cidade de São Paulo. Assim como a bacia do ribeirão do Paiol concentra as nascentes do rio Sapucaí-Mirim, um os mais importantes tributários do rio Grande, responsável pelo abastecimento de vários municípios do sul de Minas Gerais. Ambos os rios são de grande interesse socioambiental e se desenvolvem em ambientes de alta fragilidade ambiental, caracterizando estas sub-bacias como áreas prioritárias à preservação.

Já na porção oeste da APA, principalmente nos trechos circundantes à rodovia Fernão Dias, as áreas de alta fragilidade ocorrem onde a expansão urbana é mais desordenada, e, nas demais áreas desta porção da APA, as mais frágeis são aquelas que concentram cultivos anuais e pastagens degradadas e vias não pavimentadas.

Quadro 3: Síntese das relações entre o grau de fragilidade e demais características das bacias hidrográficas da APA Fernão Dias - MG.

\begin{tabular}{|c|c|c|c|c|c|c|}
\hline \multirow[t]{2}{*}{$\mathrm{BACIA}$} & $\begin{array}{c}\text { GRAU DE } \\
\text { FRAGILIDADE }\end{array}$ & USO DO SOLO & $\begin{array}{c}\text { DENSIDADE } \\
\text { POPULACIONAL }\end{array}$ & $\begin{array}{l}\text { DENSIDADE DE } \\
\text { PROCESSOS }\end{array}$ & $\mathrm{POCl}$ & \multirow{2}{*}{$\begin{array}{l}\text { ZONAS } \\
\text { DE } \\
\text { MANEJO }\end{array}$} \\
\hline & 1 & 2 & 3 & 4 & 5 & \\
\hline Rio Capivari & 86,90 & $\begin{array}{l}\text { Pastagem }(37,03) \\
\text { Remanescentes } \\
\text { florestais }(34,75) \\
\text { Cultivos agrícolas } \\
(18,94)\end{array}$ & 30,18 & $\begin{array}{l}\text { Escorregamento } \\
-(0,03) \\
\text { Ravina - }(0,06) \\
\text { Total- }(0,09)\end{array}$ & 50 a 60 & $\begin{array}{l}\text { ZCCAA - } \\
(82,32) \\
\text { ZCVS - } \\
(11,93) \\
\text { ZPVS - } \\
(3,77) \\
\text { ZOA - } \\
(1,98) \\
\text { ZOEU - } \\
(1,93)\end{array}$ \\
\hline $\begin{array}{l}\text { Ribeirão do } \\
\text { Juncal }\end{array}$ & 78,59 & $\begin{array}{l}\text { Remanescentes } \\
\text { florestais } \\
(53,96) \\
\text { Silvicultura de } \\
\text { pinus e eucalipto }\end{array}$ & 14,43 & $\begin{array}{l}\text { Escorregamento } \\
-(0,02) \\
\text { Ravina - }(0,10) \\
\text { Total - }(0,12)\end{array}$ & 47 a 60 & $\begin{array}{l}\text { ZCCAS - } \\
(67,26) \\
\text { ZCVS - } \\
(22,74) \\
\text { ZCCAA - }\end{array}$ \\
\hline
\end{tabular}




\begin{tabular}{|c|c|c|c|c|c|c|}
\hline \multirow[t]{3}{*}{ BACIA } & $\begin{array}{c}\text { GRAU DE } \\
\text { FRAGILIDADE }\end{array}$ & USO DO SOLO & $\begin{array}{c}\text { DENSIDADE } \\
\text { POPULACIONAL }\end{array}$ & $\begin{array}{c}\text { DENSIDADE DE } \\
\text { PROCESSOS }\end{array}$ & $\mathrm{POCl}$ & \multirow{2}{*}{$\begin{array}{l}\text { ZONAS } \\
\text { DE } \\
\text { MANEJO }\end{array}$} \\
\hline & 1 & 2 & 3 & 4 & 5 & \\
\hline & & $\begin{array}{l}-(21,44) \\
\text { Pastagem } \\
(18,94)\end{array}$ & & & & $\begin{array}{l}(7,87) \\
\text { ZOA } \\
(1,61) \\
\text { ZPVS } \\
(0,49) \\
\end{array}$ \\
\hline $\begin{array}{l}\text { Ribeirão do } \\
\text { Paiol }\end{array}$ & 75,72 & $\begin{array}{l}\text { Remanescentes } \\
\text { florestais } \\
(48,39) \\
\text { Pastagem } \\
(25,58) \\
\text { Silvicultura de } \\
\text { pinus e eucalipto } \\
\text { - }(14,09) \\
\text { Cultivos agrícolas } \\
-9,88)\end{array}$ & 34,75 & $\begin{array}{l} \\
\text { Escorregamento } \\
\text { - }(0,01) \\
\text { Ravina - }(0,03) \\
\text { Total - }(0,03)\end{array}$ & 50 a 60 & $\begin{array}{l}\text { ZCCAA } \\
(50,80) \\
\text { ZCCAS } \\
(33,36) \\
\text { ZDI } \\
(6,36) \\
\text { ZCVS } \\
(4,83) \\
\text { ZOEU } \\
(3,83) \\
\end{array}$ \\
\hline $\begin{array}{ll}\text { Córrego } & \text { da } \\
\text { Cachoeira } & \end{array}$ & 67,98 & $\begin{array}{l}\text { Pastagem } \\
(34,76) \\
\text { Cultivos agrícolas } \\
-(32,61) \\
\text { Remanescentes } \\
\text { florestais } \\
(23,15)\end{array}$ & 48,49 & $\begin{array}{l}\text { Escorregamento } \\
-(0,13) \\
\text { Ravina - }(0,61) \\
\text { Total- }(0,74)\end{array}$ & 46 a 50 & $\begin{array}{l}\text { ZCCAA } \\
(91,57) \\
\text { ZCVS } \\
(8,43)\end{array}$ \\
\hline $\begin{array}{l}\text { Ribeirão do } \\
\text { Pinhal }\end{array}$ & 54,30 & $\begin{array}{l}\text { Pastagem } \\
(30,85) \\
\text { Remanescentes } \\
\text { florestais } \\
(30,20) \\
\text { Cultivos agrícolas } \\
\text { - }(28,42) \\
\text { Solo exposto - } \\
(4,20)\end{array}$ & 83,53 & $\begin{array}{l}\text { Escorregamento } \\
-(0,18) \\
\text { Ravina - }(0,50) \\
\text { Total - }(0,67)\end{array}$ & 45 a 50 & $\begin{array}{l}\text { ZCCAA } \\
(74,65) \\
\text { ZDI } \\
(9,24) \\
\text { ZCCAS } \\
(7,64) \\
\text { ZCVS } \\
(4,83) \\
\text { ZOA } \\
(2,55) \\
\text { ZPVS } \\
(1,10) \\
\end{array}$ \\
\hline $\begin{array}{l}\text { Córrego do } \\
\text { Campestre }\end{array}$ & 46,46 & $\begin{array}{l}\text { Cultivos agrícolas } \\
-(36,23) \\
\text { Pastagem } \\
(28,13) \\
\text { Remanescentes } \\
\text { florestais } \\
(21,08) \\
\text { Solo exposto - } \\
(8,70)\end{array}$ & 42,74 & $\begin{array}{l}\text { Escorregamento } \\
-(0,07) \\
\text { Ravina - }(1,22) \\
\text { Total - }(1,28)\end{array}$ & 45 a 50 & $\begin{array}{c}\text { ZCCAA } \\
(98,19) \\
\text { ZOEU } \\
(1,81)\end{array}$ \\
\hline $\begin{array}{l}\text { Rio Sapucaí- } \\
\text { Mirim }\end{array}$ & 45,39 & $\begin{array}{l}\text { Pastagem } \\
(35,56) \\
\text { Cultivos agrícolas } \\
-(30,26) \\
\text { Remanescentes } \\
\text { florestais } \\
(27,71)\end{array}$ & 29,16 & $\begin{array}{l}\text { Escorregamento } \\
-(0,13) \\
\text { Ravina - }(0,22) \\
\text { Total - }(0,35)\end{array}$ & 45 a 60 & $\begin{array}{l}\text { ZCCAA } \\
(84,74) \\
\text { ZDI } \\
(15,27) \\
\text { ZOEU } \\
(0,44)\end{array}$ \\
\hline $\begin{array}{l}\text { Ribeirão dos } \\
\text { Poncianos }\end{array}$ & 41,64 & $\begin{array}{l}\text { Remanescentes } \\
\text { florestais } \\
(51,40) \\
\text { Silvicultura de } \\
\text { pinus e eucalipto } \\
-(30,81)\end{array}$ & 3,27 & $\begin{array}{l}\text { Escorregamento } \\
\text { - }(0,07) \\
\text { Ravina - }(0,30) \\
\text { Total - }(0,16)\end{array}$ & 47 a 50 & $\begin{array}{l}\text { ZCCAS } \\
(70,17) \\
\text { ZCVS } \\
(22,13) \\
\text { ZOEU } \\
(6,18) \\
\text { ZOA } \\
(1,52)\end{array}$ \\
\hline
\end{tabular}




\begin{tabular}{|c|c|c|c|c|c|c|}
\hline \multirow[t]{2}{*}{ BACIA } & $\begin{array}{c}\text { GRAU DE } \\
\text { FRAGILIDADE }\end{array}$ & USO DO SOLO & $\begin{array}{c}\text { DENSIDADE } \\
\text { POPULACIONAL }\end{array}$ & $\begin{array}{l}\text { DENSIDADE DE } \\
\text { PROCESSOS }\end{array}$ & $\mathrm{POCl}$ & \multirow{2}{*}{$\begin{array}{c}\text { ZONAS } \\
\text { DE } \\
\text { MANEJO }\end{array}$} \\
\hline & 1 & 2 & 3 & 4 & 5 & \\
\hline $\begin{array}{l}\text { Ribeirão } \\
\text { Sertão Grande }\end{array}$ & 38,07 & $\begin{array}{l}\text { Cultivos agrícolas } \\
-(33,88) \\
\text { Pastagem } \\
(32,45) \\
\text { Remanescentes } \\
\text { florestais } \\
(25,48)\end{array}$ & 36,94 & $\begin{array}{l}\text { Escorregamento } \\
-(0,20) \\
\text { Ravina - }(0,59) \\
\text { Total - }(0,78)\end{array}$ & 45 a 47 & $\begin{array}{l}\text { ZCCAA - } \\
(99,76) \\
\text { ZOEU - } \\
(0,24)\end{array}$ \\
\hline $\begin{array}{l}\text { Rio } \\
\text { Camanducaia }\end{array}$ & 28,04 & $\begin{array}{l}\text { Pastagem } \\
(30,81) \\
\text { Remanescentes } \\
\text { florestais } \\
(30,47) \\
\text { Cultivos agrícolas } \\
\text { - }(28,81) \\
\text { Solo exposto - } \\
(5,92)\end{array}$ & 84,75 & $\begin{array}{l}\text { Escorregamento } \\
-(0,17) \\
\text { Ravina - }(0,60) \\
\text { Total - }(0,76)\end{array}$ & 40 a 47 & $\begin{array}{l}\text { ZCCAA - } \\
(79,67) \\
\text { ZOEU - } \\
(15,50) \\
\text { ZDI - } \\
(4,83)\end{array}$ \\
\hline Rio Jaguari & 22,61 & $\begin{array}{l}\text { Remanescentes } \\
\text { florestais } \\
(32,79) \\
\text { Cultivos agrícolas } \\
-(25,75) \\
\text { Pastagem } \\
(25,05) \\
\text { Urbano - }(4,59)\end{array}$ & 382,99 & $\begin{array}{l}\text { Escorregamento } \\
-(0,15) \\
\text { Ravina - }(0,63) \\
\text { Total - }(0,78)\end{array}$ & 40 a 45 & $\begin{array}{l}\text { ZCCAA - } \\
(44,03) \\
\text { ZOEU - } \\
(34,19) \\
\text { ZCVS - } \\
(10,99) \\
\text { ZDI - } \\
(6,54) \\
\text { ZPVS - } \\
(4,24) \\
\end{array}$ \\
\hline $\begin{array}{l}\text { Ribeirão das } \\
\text { Posses }\end{array}$ & 19,36 & $\begin{array}{l}\text { Remanescentes } \\
\text { florestais } \\
(30,95) \\
\text { Pastagem } \\
(29,52) \\
\text { Cultivos agrícolas } \\
\text { - }(28,04) \\
\text { Silvicultura de } \\
\text { pinus e eucalipto } \\
-(8,09)\end{array}$ & 47,95 & $\begin{array}{l}\text { Escorregamento } \\
-(0,15) \\
\text { Ravina - }(0,72) \\
\text { Total - }(0,88)\end{array}$ & 40 a 47 & $\begin{array}{l}\text { ZCCAA - } \\
(79,87) \\
\text { ZCCAS - } \\
(8,99) \\
\text { ZCVS - } \\
(6,61) \quad- \\
\text { ZOEU - } \\
(4,63) \quad-\end{array}$ \\
\hline $\begin{array}{l}\text { Córrego do } \\
\text { Abel }\end{array}$ & 18,37 & $\begin{array}{l}\text { Remanescentes } \\
\text { florestais } \\
(50,48) \\
\text { Silvicultura de } \\
\text { pinus e eucalipto } \\
-(23,80) \\
\text { Pastagem } \\
(15,11) \\
\text { Cultivos agrícolas } \\
-(8,29)\end{array}$ & 55,97 & $\begin{array}{l}\text { Escorregamento } \\
\text { - }(0,07) \\
\text { Ravina - }(0,25) \\
\text { Total - }(0,32)\end{array}$ & 45 a 50 & $\begin{array}{l}\text { ZCCAS - } \\
(51,36) \\
\text { ZCCAA - } \\
(40,14) \\
\text { ZCVS - } \\
(5,07) \\
\text { ZPVS - } \\
(3,43)\end{array}$ \\
\hline $\begin{array}{l}\text { Ribeirão } \\
\text { Vargem } \\
\text { Grande }\end{array}$ & 15,52 & $\begin{array}{l}\text { Remanescentes } \\
\text { florestais } \\
(38,53) \\
\text { Pastagem } \\
(30,26) \\
\text { Cultivos agrícolas } \\
\text { - }(21,68)\end{array}$ & 28,35 & $\begin{array}{l}\text { Escorregamento } \\
-(0,14) \\
\text { Ravina - }(0,33) \\
\text { Total - }(0,46\end{array}$ & 40 a 47 & $\begin{array}{l}\text { ZCCAA - } \\
(83,69) \\
\text { ZCVS - } \\
(16,31) \\
\text { ZOEU - } \\
(1,82)\end{array}$ \\
\hline $\begin{array}{l}\text { Córrego do } \\
\text { Alegre }\end{array}$ & 4,05 & \begin{tabular}{ll}
\multicolumn{2}{l}{ Remanescentes } \\
florestais & - \\
$(40,00)$ & \\
Pastagem & - \\
$(37,90)$ &
\end{tabular} & 107,4 & $\begin{array}{l}\text { Escorregamento } \\
-(0) \\
\text { Ravina - }(0,52) \\
\text { Total - }(0,52)\end{array}$ & 40 a 45 & $\begin{array}{l}\text { ZCCAA - } \\
(100,00)\end{array}$ \\
\hline
\end{tabular}




\begin{tabular}{|c|c|c|c|c|c|c|}
\hline \multirow[t]{3}{*}{$\mathrm{BACIA}$} & $\begin{array}{c}\text { GRAU DE } \\
\text { FRAGILIDADE }\end{array}$ & USO DO SOLO & $\begin{array}{c}\text { DENSIDADE } \\
\text { POPULACIONAL }\end{array}$ & $\begin{array}{l}\text { DENSIDADE DE } \\
\text { PROCESSOS }\end{array}$ & $\mathrm{POCl}$ & \multirow{2}{*}{$\begin{array}{c}\text { ZONAS } \\
\text { DE } \\
\text { MANEJO }\end{array}$} \\
\hline & 1 & 2 & 3 & 4 & 5 & \\
\hline & & $\begin{array}{l}\text { Cultivos agrícolas } \\
-(16,68)\end{array}$ & & & & \\
\hline $\begin{array}{l}\text { Ribeirão das } \\
\text { Anhumas }\end{array}$ & 1,85 & $\begin{array}{l}\text { Cultivos agrícolas } \\
-(37,16) \\
\text { Remanescentes } \\
\text { florestais } \\
(30,68) \\
\text { Pastagem } \\
(25,61)\end{array}$ & 21,39 & $\begin{array}{l}\text { Escorregamento } \\
-(0) \\
\text { Ravina - }(0,09) \\
\text { Total - }(0,09)\end{array}$ & 40 a 45 & $\begin{array}{l}\text { ZCCAA - } \\
(96,97) \\
\text { ZDI - } \\
(3,03)\end{array}$ \\
\hline
\end{tabular}

${ }^{1}$ Percentagem da área da bacia com fragilidade ambiental à ocorrência de processos erosivos e movimentos de massa com valores fuzzy $\geq$ ao valor médio $-0,337 ;^{2}$ Categorias de uso do solo que ocupam maior área na bacia, com percentual de ocupação, estimado a partir da intersecção dos limites das bacias com as classes de uso; ${ }^{3} \mathrm{Hab} . / \mathrm{km}^{2}$ estimado a partir da interseç̧ão dos limites das bacias com os setores censitários; ${ }^{4}$ Processos $/ \mathrm{km}^{2}$ estimado a partir da intersecção dos limites das bacias com os processos erosivos e movimentos de massa; ${ }^{5}$ Zonas de manejo predominantes e, percentual da área da bacia reservada a estas zonas; ${ }^{6}$ Valores de POCI predominantes; ZCCAA: Zona de conservação com concentração de atividades agropastoris; ZCCAV: Zona de conservação com concentração de atividades silviculturais; ZDI: Zona de Desenvolvimento Industrial; ZOEU: Zona de ocupação e expansão urbana: ZPVS: Zona de proteção da vida silvestre; ZCVS: Zona de conservação da vida silvestre; ZOA: Zona de ocorrência ambiental.

\section{CONCLUSÕES}

O procedimento apresentado neste artigo é uma contribuição aos estudos que tenham como propósito o mapeamento de áreas de risco à erosão. A abordagem sistêmica, em conjunto com a análise espacial, permitiu uma análise integrada da paisagem da APA Fernão Dias, de modo que, os resultados apresentados pelo mapeamento da fragilidade ambiental refletem a realidade do campo, e podem ser utilizados como prognóstico de cenários futuras desta unidade de conservação.

O mapeamento dos processos erosivos e dos movimentos de massa, a partir de imagens disponibilizadas pela plataforma Google Earth possibilitou a análise detalhada com relação a localização dos referidos processos.O uso do índice de vegetação como 
variável do mapeamento da fragilidade ambiental possibilitou estimar o grau de proteção do solo proporcionado pela densidade de biomassa da cobertura de cada um dos tipos de uso do solo.

A técnica empregada para a espacialização da ocorrência de chuva intensa (maior ou igual a $50 \mathrm{~mm} / 24 \mathrm{hs}$ ) se mostrou eficaz, tendo sido observada a correspondência entre áreas com elevada probabilidade de chuvas intensas e altitudes mais elevadas, caracterizando a ocorrência de eventos orográficos. Tal abordagem pode contribuir com estudos que tenham como propósito mapear áreas propícias a desastres naturais, indicando aquelas onde precipitações de alta intensidade têm maior probabilidade de ocorrência durante o verão.

A aplicação do estimador kernel para a geração da densidade de lineamentos estruturais e densidade de vias de circulação destacou locais onde os valores destas variáveis são mais elevados. Foi observada a associação entre alta densidade de vias nas imediações da rodovia Fernão Dias, em áreas agropastoris e de silvicultura; alta densidade de lineamentos estruturais nas áreas de cabeceiras, principalmente nos locais em que a drenagem se desenvolve em ambiente litológico altamente estruturado.

O método proposto para determinação dos pesos atribuídos às variáveis ambientais baseado em teste estatístico Kolmogorov-Smirnov alcançou resultados satisfatórios, e respeita as especificidades de cada local. No contexto da APA Fernão Dias-MG verificou-se que as variáveis que apresentam maior peso no condicionamento de processos erosivos e movimentos de massa são, respectivamente, nesta ordem: índice de vegetação, intensidade da chuva, declividade, densidade de vias de circulação e densidade de lineamentos estruturais.

A álgebra dos mapas referentes às variáveis ambientais representadas em conjunto fuzzy tornou os resultados maios coerentes com a realidade, pois considerou as áreas de transição de cada variável e não se restringiu às classes de fragilidades, com limites rígidos. 
Os resultados obtidos mostraram que algumas áreas da APA Fernão Dias devem ser monitoradas e fiscalizadas a fim de se evitar o uso intensivo agrícola dos sistemas ambientais e a expansão urbana desordenada. Espera-se que o procedimento metodológico aqui apresentado possa contribuir como instrumento de planejamento ambiental de bacias hidrográficas e de municípios situados em outras áreas de proteção ambiental.

\section{AGRADECIMENTOS}

À Fundação de Amparo à Pesquisa do Estado de São Paulo - FAPESP, pelo auxílio recebido (Processo 2011/05125-0).

\section{BIBLIOGRAFIA}

AKGUN, A.; TURK, N. Mapping erosion susceptibility by a multivariate statistical method: a case study from the Ayvalık region, NW Turkey. Computers e Geosciences, 37 (9): 1515-1524, 2011.

AMORIM, R.F.; SILVA, F.M. Modelagem do processo de vulnerabilidade à erosão do solo utilizando o SPRING. In: Simpósio Brasileiro de Sensoriamento Remoto, 14, 2009, Natal, Anais. Natal: INPE, 2009. p. 5073-5080.

AVERY, T. E.; BERLIN, G. L. Interpretation of Aerial Photographs. 4a ed. Minneapolis: Burgess Publishing Company, 1985. 554p.

BERTONI, J.; LOMBARDI NETO, F. Conservação do solo. 4ạ Ed. São Paulo: Ícone, 1999. 480p.

BIGARELLA, J. J., BECKER, R. D., SANTOS, G. F. dos. Estrutura e origem das paisagens tropicais e subtropicais. 2a ed. Florianópolis: Ed. da UFSC, 2007. 1436 p. v.3.

BOU KHEIR, R.; WILSON, J.; DENG, Y. Use of terrain variables for mapping gully erosion susceptibility in Lebanon. Earth Surface Processes and Landforms,32 (12):1770-1782, 2007.

BURROUGH, P. A.; MCDONELL, R. A. Principles of Geographical Information Systems. 2a ed. New York: Oxford University Press, 1998, 190 pp.

CALIJURI, M. L.; ALVES, J. E. M.; BAPTISTA, A. C.; SANTIAGO, A. F.; LOURES, S. S. P. Proposta metodológica para geração da carta de fragilidade ambiental, utilizando lógica fuzzy e combinação linear ponderada. In: XIII Simpósio Brasileiro de Sensoriamento Remoto, 13, 2007, Florianópolis, Anais... Florianópolis: INPE, 2007. p. 3311-3318.

CHAPLOT, V.; COADOU LE BROZEC, E.; SILVERA, N.; VALENTIN, C. Spatial and temporal assessment of linear erosion in catchments under sloping lands of northern Laos. Catena, 63, (2-3):167-184, 2005.

CHAVEZ, J. P.S. An improved dark-object subtraction technique for atmospheric scattering correction of multispectral data. Remote Sensing of Environment. New York, 24 (3):459-479, 1988.

GUMBEL, E.J. Statistics of Extremes. New York: Columbia University Press, 1958. 375p. 
COELHO, H. M. G. Modelo para avaliação e apoio ao gerenciamento de resíduos sólidos de indústrias. Tese (Doutorado) - Programa e Pós-graduação em Saneamento, Meio Ambiente e Recursos Hídricos da Universidade Federal de Minas Gerais, Belo Horizonte, Minas Gerais, 2011.

CONFORTI, M.; AUCELLI, P.P.C.; ROBUSTELLI, G.; SCARCIGLIA, F. Geomorphology and GIS analysis for mapping gully erosion susceptibility in the Turbolo stream catchment (Northern Calabria, Italy). Natural Hazards and Earth System Sciences, 56 (3):881-898, 2010.

CONOSCENTI, C.; AGNESI, V.; ANGILERI, S.; CAPPADONIA, C.; ROTIGLIANO, E.; MÄRKER, M. A GIS-based approach for gully erosion susceptibility modelling: a test in Sicily, Italy. Environmental Earth Sciences, 70 (3):1179-1195, 2013.

CONOSCENTI, C.; ANGILERI, S.; CAPPADONIA, C.; ROTIGLIANO, E.; AGNESI, V.; MÄRKER, M.Gully erosion susceptibility assessment by means of GIS-based logistic regression: A case of Sicily (Italy). Geomorphology, 204 (1):399-411, 2014.

CONOSCENTI, C.; DI MAGGIO, C.; ROTIGLIANO, E. Soil erosion susceptibility assessment and validation using a geostatistical multivariate approach: a test in Southern Sicily. Natural Hazard, 46(3):287-305, 2008.

CREPANI, E.; MEDEIROS, J.S.; AZEVEDO, L.G.; DUARTE, V.; HERNANDEZ, P.; FLORENZANO, T. Curso de Sensoriamento Remoto Aplicado ao Zoneamento Ecológico-Econômico. São José dos Campos: INPE, 1996.

EVERITT, B. S. The Cambridge Dictionary of Estatistics. 3a ed. Cambridge University Press, Cambridge, United Kingdom, 2006.

FIORI, A. P. Fatores que influem na análise de vertentes e no movimento de massa em encostas. Boletim Paranaense de Geografia, 43, p.7-24, 1995.

FERREIRA, M.C. - Iniciação à análise geoespacial. São Paulo, Editora UNESP, 2014.

FORMAN, R. T. T.; ALEXANDER, L. E. Roads and their major ecological effects. Annual Reviews in Ecology e Systematics, 29:207-231, 1998.

FUKS, S. D. Novos modelos para mapas derivados de informações de solo. In: ASSAD, E. D.; SANO, E. E. Sistemas de Informações Geográficas: Aplicações na Agricultura. 2a ed. EMPRAPA, Brasília, p. 373-410, 1998.

GEISSEN, V.; KAMPICHLER, C.; LOPEZ-DE LLERGO-JUAREZ, J.J.; GALINDO-ACANTARA, A. Superficial and subterranean soil erosion in Tabasco, tropical Mexico: development of a decision tree modeling approach. Geoderma, 139 (3-4):277-287, 2007.

GOMEZ GUTIERREZ, A.; SCHNABEL, S.; FELICÍSIMO, Á.M. Modelling the occurrence of gullies in rangelands of southwest Spain. Earth Surface Processes and Landforms, 34 (14):1894-1902, 2009a.

GOMEZ GUTIERREZ, A.; SCHNABEL, S.; CONTADOR, F, L. Using and comparing two nonparametric methods (CART and MARS) to model the potential distribution of gullies. Ecological Modelling, 220 (24):3630-3637, 2009b.

HUGHES, A.O., PROSSER, I.P., STEVENSON, J., SCOTT, A., LU, H., GALLANT, J., MORAN, C.J. Gully Erosion Mapping for the National Land and Water Resources Audit. Canberra: CSIRO Land and Water Technical report, 2001. 19p.

KHEIR, R. B.; CERDAN, O.; ABDALLAH, C. Regional soil erosion risk mapping in Lebanon. Geomorphology, 82 (3-4):347-359, 2006. 
LUCÀ, F., CONFORTI, M., ROBUSTELLI, G. Comparison of GIS-based gullying susceptibility mapping using bivariate and multivariate statistics: Northern Calabria, South Italy. Geomorphology, 134 (3-4):297-308, 2011.

MAGLIULO, P. Assessing the susceptibility to water-induced soil erosion using a geomorphological, bivariate statistics-based approach. Environmental Earth Sciences, 67 (6):1801-1820, 2012.

MAGLIULO, P. Soil erosion susceptibility maps of the Janare Torrent Basin (Southern Italy). Journal of Maps, 6:435-447, 2010.

MARKER, M., PELACANI, S., SCHRODER, B. A functional entity approach to predict soil erosion processes in a small Plio-Pleistocene Mediterranean catchment in Northern Chianti, Italy. Geomorphology, 125 (4):530-540, 2011.

MEYER, A., MARTINEZ-CASASNOVAS, J.A. Prediction of existing gully erosion in vineyard parcels of the NE Spain: a logistic modelling approach. Soiland Tillage Research,50 (3-4):319331,1999 .

MIARA, M. A.; OKA-FIORI, C. Análise por múltiplos critérios para a definição de níveis de fragilidade ambiental - um estudo de caso: bacia hidrográfica do rio Cará-Cará, Ponta Grossa/PR. RA'E GA, Curitiba, 13:85-98, 2007.

MOURA, A. C. M. Reflexões metodológicas como subsídio para estudos ambientais baseados em Análise de Multicritérios. In: Simpósio Brasileiro de Sensoriamento Remoto, 13, 2007, Florianópolis, Anais... Florianópolis: INPE, 2007. p.2899-2906.

MOURA, A. C. M.; MOURA, C. A.; SANTANA, S. A. DE; LANNA, L. DE S.; AZEVEDO, U. C. DE S. G.; LOURENÇO, P. M. B. Geoprocessamento nos diagnósticos e prognósticos de áreas de interesse especial ao na área de influência das linhas de transmissão da CEMIG - estudo de caso da RMBH. In: Congresso Brasileiro de Cartografia, 24, 2010, Aracaju, Anais... Aracaju, 2010. p. 1570-1578.

MURATORI, A. M. Erosão no nordeste do Paraná: uma proposta metodológica de estudo sistemático através do uso de fotografias aéreas. Dissertação de Mestrado, Universidade Federal do Paraná, Curitiba, 1983.

NIGEL, R.; RUGHOOPUTH, S.D.D.V. Soil erosion risk mapping with new datasets: An improved identification and prioritisation of high erosion risk areas. Catena, 82 (3):191-205, set. 2010.

PENTEADO, M. M. Fundamentos de geomorfologia. Rio de Janeiro: IBGE, 1974. 158 p.

PRADO, J. P. B; NÓBREGA, M.T. Determinação de perdas de solo na bacia hidrográfica do córrego Ipiranga em Cidade Gaúcha, Estado do Paraná, com aplicação da Equação Universal de Perdas de Solo (EUPS). Acta Scientiarum Technology, 27 (1):33-42, 2005.

ROSS, J. L. S. Análise empírica da fragilidade dos ambientes naturais e antropizados. Revista do Departamento de Geografia, 8:63-74, 1994.

ROUSE, J. W.; HAAS, R. H.; SCHELL, J. A.; DEERING, D. W. Monitoring vegetation systems in the Great Plains with ERTS. Earth Resources Technology Satellite Symposium, 1: 309-317, 1973.

SANTORO, J. Fenômenos erosivos acelerados na região de São Pedro - SP. Estudo da fenomenologia com ênfase geotécnica. Dissertação (Mestrado em Geotecnia e Meio Ambiente) - Instituto de Geociências e Ciências Exatas, Universidade Estadual Paulista Júlio de Mesquita Filho, Rio Claro, São Paulo, 1991.

SELBY, M. J. Hill slope materials e processes. New York: Oxford University Press, 1990. 
SILVA, A. B. Sistemas de Informações Georreferenciadas: conceitos e fundamentos. 1a ed. Campinas, SP: Ed. UNICAMP, 2003. 232p.

SILVA, J. R. C. Perdas de solo e produção de sedimentos. Dissertação (Mestrado em Solos e Nutrição de Plantas) - Escola Superior de Agricultura Luiz de Queiroz (ESALQ), Universidade de São Paulo, Piracicaba, São Paulo, 1978.

SOARES, P. C.; FIORI, A. P. Lógica e sistemática na análise interpretação de fotografias aéreas em geologia. Noticia Geomorfológica, 1976. p.107-121.

SPÖRL, C. Análise da Fragilidade Ambiental Relevo-Solo com Aplicação de Três Modelos Alternativos nas Altas Bacias do Rio Jaguari-Mirim, Ribeirão do Quartel e Ribeirão da Prata.Dissertação (Mestrado em Geografia) - Faculdade de Filosofia, Letras e Ciências Humanas (FFLCH), Universidade de São Paulo, São Paulo, 2001.

SPÖRL, C. ROSS, J. L. S. Análise comparativa da fragilidade ambiental com aplicação de três modelos.GEOUSP - Espaço e Tempo, 15:39-49, 2004.

TAYLOR, P. J. Quantitative methods in geography. Boston, Houghton MifflinCo., 1977.

TRICART, J. Ecodinâmica. Rio de Janeiro: IBGE/ SUPREN, 1977. 91p.

VALERIANO, M. M. Modelo digital de elevação com dados SRTM disponíveis para a América do Sul. São José dos Campos, SP: INPE: Coordenação de Ensino, Documentação e Programas Especiais (INPE-10550-RPQ/756) (Boletim), 2004,72p.

WISCHMEIER, W. H.; SMITH, D. D. Predicting rainfall erosion losses - A guide to conservation planning. Washington: USDA, 1978. 58p.

ZADEH, L. A. Fuzzy sets. Information and Control, 8 (3):338-353, 1965.

\begin{tabular}{cc} 
Artigo submetido em & 18/09/2014 \\
\hline Artigo aceito em & 20/03/2015
\end{tabular}

